\title{
LATIM NOS FEITIÇOS DE HARRY POTTER: ALTERNATIVA DE USO DO CINEMA NA EDUCAÇÃo
}

\author{
LATIN IN HARRY POT'TER SPELLS: ALTERNATIVE USE OF CINEMA IN \\ EDUCATION
}

iD Aline Vieira Malanovicz

Doutora em Administração

Universidade Federal do Rio Grande do Sul - UFRGS

Porto Alegre, RS - Brasil

malanovicz@gmail.com

Ana Paula Vieira Malanovicz Especialista em Psicomotricidade Mestranda em Educação

Pontifícia Universidade Católica do Rio Grande do Sul - PUCRS

Porto Alegre, RS - Brasil ana.malanovicz@gmail.com

\begin{abstract}
Resumo: O objetivo desta pesquisa é identificar as cenas de feitiços dos filmes da saga Harry Potter que podem ser utilizadas como apoio no ensino de Latim. Para tanto, exploram-se quais são as origens e as estruturas do latim utilizadas nos feitiços da referida série. O método adotado é a pesquisa filmográfica, com análise de conteúdo dos achados. São encontrados apoios para ensino de etimologia; os casos nominativo, genitivo, acusativo, dativo, ablativo e vocativo; flexões de gênero, número e caso para substantivos e adjetivos; concordâncias; conjugações verbais, tempos verbais, pessoas; outras classes gramaticais; pronúncia; dentre outros. Debatem-se os métodos tradicionais e inovadores para ensino do Latim e conclui-se que esta proposta de uso de cenas de filmes, assim como outras, oferece contribuições no sentido de ilustrar, atrair, concretizar e memorizar o conteúdo trabalhado, de maneira a despertar o interesse dos estudantes pelo seu próprio processo de aprendizagem.
\end{abstract}

Palavras-chave: educação e cinema; levantamento filmográfico; latim; Harry Potter.

Abstract: The objective of this research is to identify the spell scenes from the Harry Potter films that can be used as a support for the teaching of Latin. We explore what are the origins and structures of Latin used in the spells of the Harry Potter film series. The method adopted is film research, with content analysis of the findings. Support is found for teaching etymology; the nominative, genitive, accusative, dative, ablative and vocative cases; gender, number and case inflections for nouns and adjectives; concordances; verb conjugations, verb tenses; other grammatical classes; pronunciation; among others. The traditional and innovative methods for teaching Latin are discussed, and it is concluded that this proposal to use film scenes, as well as others, offers contributions in order to illustrate, attract, materialize and memorize the content worked, in order to arouse students' interest in their own learning process.

Keywords: education and cinema. filmographic survey. latin. Harry Potter.

Para citar - ABNT NBR 6023:2018

MALANOVICZ, Aline Vieira; MALANOVICZ, Ana Paula Vieira. Latim nos feitiços de Harry Potter: alternativa de uso do Cinema na Educação. Cadernos de Pós-graduação, São Paulo, v. 20, n. 1, p. 16-38, jan./jun. 2021. Disponível em:

https://doi.org/10.5585/cpg.v20n1.19776. 
Introdução

A atual oposição entre alunos Nativos Digitais (PRENSKY, 2001) e escolas que oferecem ensino baseado somente em leitura e escrita destaca o amplo potencial do uso de filmes como procedimento de ensino para a superação da pedagogia tradicional centrada na exposição do conteúdo, por parte do professor, e na assimilação passiva desse conteúdo, por parte do aluno (CAMPOS et al., 2019). O cinema, quando trabalhado em aula, vai além do entretenimento e da diversão, pois também desenvolve a capacidade de observação, reflexão e crítica do aluno, bem como permite maior facilidade de fixação do conteúdo e torna tanto a aula quanto a aprendizagem mais efetivas e significativas (BACICH, 2017).

Nessa perspectiva, o Cinema apresenta amplo potencial de contribuição para o processo de ensino-aprendizagem escolar, ao mesmo tempo em que diverte os espectadores. Por isso, o recurso a obras cinematográficas para complementar o conteúdo ministrado em sala de aula ou para sensibilizar os alunos em relação ao conteúdo tem sido bastante utilizado. Nesse sentido, considera-se que "o professor que se utiliza do recurso cinematográfico para ensinar em suas aulas de história, geografia, português, é um profissional que sabe usar essa ferramenta a seu favor" (RODRIGUES; COMERLATO, 2018, p. 35-47).

$\mathrm{Na}$ formação escolar de crianças e jovens, ainda resiste, em alguns colégios, a disciplina de Latim (GAZETA, 2019; CORREA, 2018; FUNDAÇÃO TORINO, 2018; BAND, 2017). Trabalhos acadêmicos analisam os métodos para o ensino da língua latina aplicados na atualidade (UFRGS, 2021; ALVES et al., 2017; RIBEIRO, 2015; UFBA, 2015). Dentre os exemplos de recursos "que aproximam o mundo clássico da realidade atual” (UFRGS, 2021), estão fatores de atração para o Latim, como filmes e a série Harry Potter (NASCIMENTO, 2012), pois: "algumas das palavras usadas pela autora da série, J.K.Rowling, nos feitiços foram tiradas diretamente do Latim" (EXAME, 2016, p. 1).

O objetivo desta pesquisa é identificar as cenas de feitiços dos filmes Harry Potter que podem ser utilizadas como apoio no ensino de Latim. Para tanto, o presente artigo está organizado em cinco seções, além desta introdução. $\mathrm{Na}$ segunda seção, apresenta-se a revisão de literatura, que versa sobre o uso de filmes na educação, o ensino de Latim e a saga literária e cinematográfica Harry Potter. Já na terceira seção, informa-se o método empregado neste estudo. Por sua vez, na quarta e na quinta seções, expõem-se os resultados e sua discussão, respectivamente. E, na última seção, delineiam-se as considerações finais. 


\section{Revisão de Literatura}

Esta seção apresenta a revisão de literatura que fornece as bases conceituais para a pesquisa aqui reportada. Em termos de estruturação, a presente seção está organizada com a exposição de quadros de breves revisões bibliográficas sobre os seguintes temas: educação e cinema; ensino de Latim; série Harry Potter.

Quanto aos temas educação e cinema, percebe-se, em rápida consulta a repositórios de artigos científicos e outros trabalhos acadêmicos, uma variedade bastante expressiva de estudos brasileiros que, nos últimos anos, relatam aplicações do uso de filmes no ensino escolar (Quadro 1).

Quadro 1 - Exemplos de uso de filmes no ensino de disciplinas escolares

\begin{tabular}{|l|l|l|l|}
\hline Disciplina & Título da Pesquisa & Autoria & Ano \\
\hline Ciências & Ouso de recursos audiovisuais no ensino de Ciências & BERKe ROCHA & 2019 \\
\hline $\begin{array}{l}\text { Língua } \\
\text { Portuguesa }\end{array}$ & $\begin{array}{l}\text { Hábito da leitura através de filmes no ensino de } \\
\text { Língua Portuguesa: um olhar sobre esta prática com } \\
\text { alunos do 2o anos "6" do Ensino Médio da Escola } \\
\text { Estadual Duque de Caxias em Tabatinga-AM }\end{array}$ & SILVA e OBANDO & 2019 \\
\hline Química & $\begin{array}{l}\text { Uso de filmes no ensino de radioatividade: uma } \\
\text { estratégia motivadora para aulas do nivel médio }\end{array}$ & CAMPOS e colegas & 2019 \\
\hline Geografia & $\begin{array}{l}\text { Levantamento de obras cinematográficas para } \\
\text { utilização no ensino de Geografia }\end{array}$ & NEZ e LEITE & 2018 \\
\hline Artes & $\begin{array}{l}\text { Oficina de Cinema na Escola: uma Nova Proposta } \\
\text { Pedagógica }\end{array}$ & $\begin{array}{l}\text { RODRIGUESe } \\
\text { COMERLATO }\end{array}$ & 2018 \\
\hline Geografia & OCinema no Ensino de Geografia & VOTTO & 2017 \\
\hline $\begin{array}{l}\text { Ciências, } \\
\text { Matemática, } \\
\text { Língua } \\
\text { Portuguesa }\end{array}$ & $\begin{array}{l}\text { Importância da Inserção de Filmes e Vídeos na } \\
\text { Prática Docente }\end{array}$ & CARVALHO & 2017 \\
\hline Sociologia & $\begin{array}{l}\text { Utilização do cinema no ensino de Sociologia: o que } \\
\text { os professores têm a dizer? }\end{array}$ & ANGREWSKI & 2015 \\
\hline História & Cinema e educação: o uso de filmes na escola & SILVA & 2014 \\
\hline
\end{tabular}

Fonte: Pesquisa bibliográfica realizada pelas autoras.

Os resultados de um dos levantamentos revelam que "há pertinência na utilização dos recursos audiovisuais como metodologia que contribui para o processo de ensino-aprendizagem dos discentes" (BERK; ROCHA, 2019, p. 85). Da mesma forma, "Muitas vezes os vídeos ajudam a ver elementos que aparecem estáticos em livros e textos. A sensação de movimento e interação foi fundamental para trabalhar conteúdos de uma maneira mais leve, clara, concisa, ou aprofundada" (ANGREWSKI, 2015). Alguns dos diversos benefícios do uso de filmes no ensino estão resumidos brevemente no Quadro 2, a seguir. 
Quadro 2 - Benefícios do uso de filmes no ensino

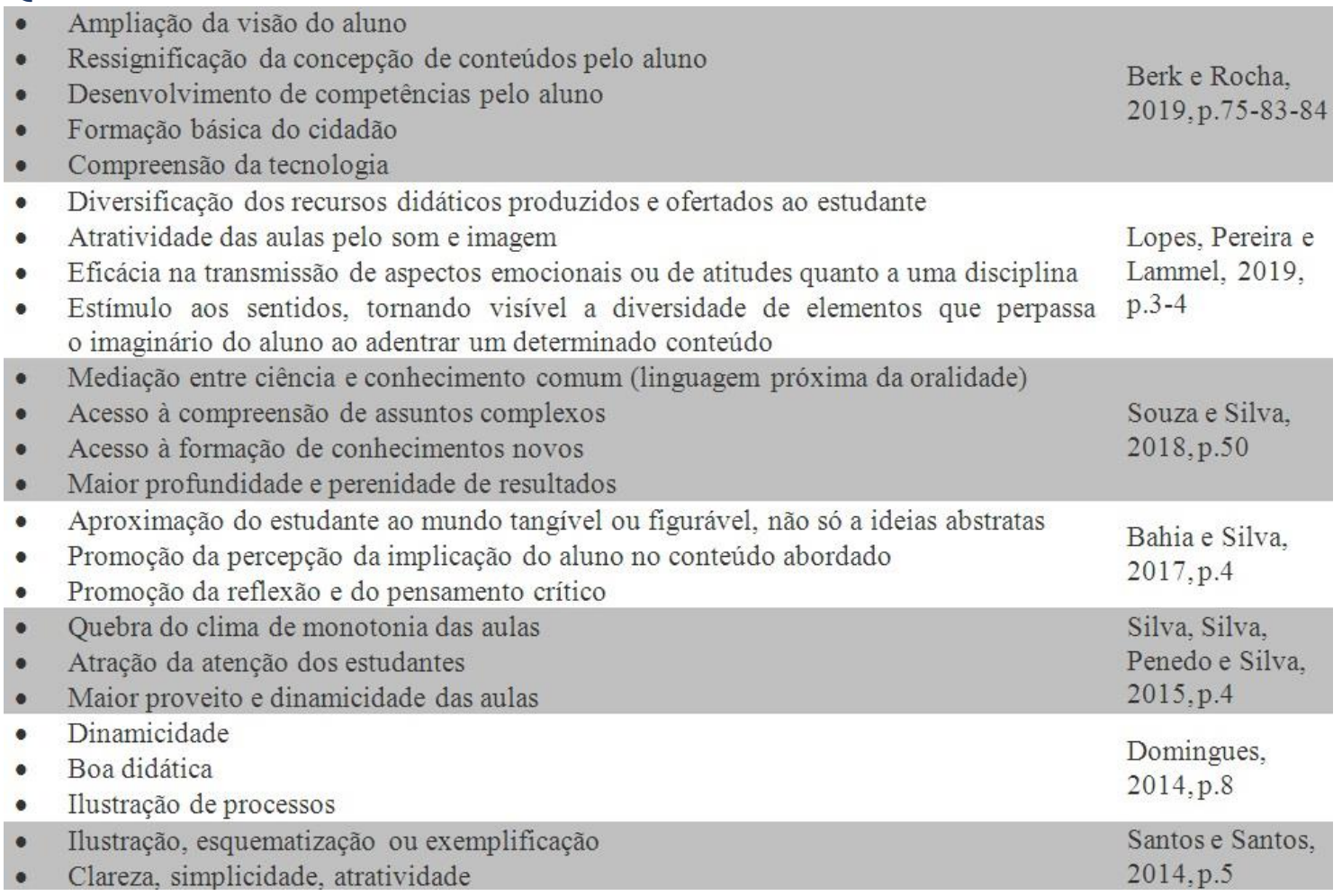

Fonte: Malanovicz (2020).

Os processos de mudanças nas diretrizes da educação nacional "envolvem diversos fatores sociais que sempre levaram ao debate da importância do ensino do latim" (ALVES et al., 2017). Argumentos para sua defesa são dados em trabalhos acadêmicos (CORREA, 2018; ALVES et al., 2017; UFBA, 2015) e em notícias (GAZETA, 2019):

Desde o início do século passado, estudos norte-americanos têm demonstrado as vantagens do ensino das línguas clássicas para o desenvolvimento do raciocínio lógico, da proficiência na língua materna (em termos de vocabulário, gramática e leitura) e para o aprendizado de outras línguas indo-europeias. (CORREA, 2018, p. 122).

No Brasil, o Latim é ensinado em faculdades (UFRGS, UFRJ, UFPB, UFBA, UNEB, USP, UNESP, Unicamp, UFSC) e em algumas escolas (EMEF Des. Amorim Lima, em São Paulo/SP; Fundação Torino, em Nova Lima/MG; Colégio Pedro II, no Rio de Janeiro/RJ). Além disso, o ensino do idioma vem sendo oferecido em cursos e plataformas on-line (Latinitas, Omnia), conforme demonstra o quadro 3: 
Dossiê Educacão e Cinema: atos formativos

Quadro 3 - Alguns colégios e universidades que oferecem o ensino de Latim

\begin{tabular}{|c|c|}
\hline Colégio / Universidade & Destaques \\
\hline $\begin{array}{l}\text { EMEF Des. Amorim Lima } \\
\text { e UFRGS, UFRJ, Instituto } \\
\text { Angelicum, França, } \\
\text { Portugal (GAZETA, 2019) }\end{array}$ & $\begin{array}{l}\text { Na EMEF Des. Amorim Lima, o Latim é oferecido para os alunos do 40 ano. } \\
\text { Projetos semelhantes têm sido implementados em outras cidades, como } \\
\text { Porto Alegre (em parceria com a UFRGS) e Rio de Janeiro (UFRJ). } \\
\text { O Instituto Angelicum, sediado no Rio de Janeiro, oferece desde } 2016 \text { um } \\
\text { curso de latim específico para crianças. Mais de } 200 \text { alunos já passaram } \\
\text { pela plataforma, que é } 100 \% \text { digital. As aulas são em vídeos de } 30 \text { minutos. } \\
\text { Na França, mais de } 10 \% \text { dos alunos do ensino básico cursam latim } \\
\text { Em } 2015 \text {, o governo português também iniciou um projeto para que as } \\
\text { duas línguas clássicas, então restritas aos dois últimos anos do ensino } \\
\text { médio, fossem oferecidas também nos anos iniciais. }\end{array}$ \\
\hline $\begin{array}{l}\text { Fundação Torino } \\
\text { (FUNDAÇÃO, 2018) }\end{array}$ & $\begin{array}{l}\text { Escola Internacional: Dependendo da opção que fizerem para o Ensino } \\
\text { Médio, os alunos também têm a oportunidade de estudar o latim. }\end{array}$ \\
\hline França (EL PAÍS, 2018) & $\begin{array}{l}\text { Resgate das línguas clássicas no ensino está entre as novas prioridades do } \\
\text { Governo francês. (...) Na França, 12,25\% dos alunos estudam latim. }\end{array}$ \\
\hline $\begin{array}{l}\text { EMEF Des. Amorim Lima } \\
\text { (CORREA, 2018) }\end{array}$ & $\begin{array}{l}\text { A escola recebeu o projeto no início de } 2013 \text { com grande entusiasmo. (...) } \\
\text { aulas de latim e grego na grade curricular, para todos os alunos } \\
\text { respectivamente dos } 4 \text { e e } 7 \stackrel{0}{a} \text { anos, nos turnos da manhã e da tarde. }\end{array}$ \\
\hline UFPB (ALVES et al. 2017) & $\begin{array}{l}\text { Hoje, na Universidade Federal da Paraíba, o latim está presente apenas nos } \\
\text { cursos de Letras Clássicas e Letras Vernáculas. }\end{array}$ \\
\hline $\begin{array}{l}\text { EMEF Des. Amorim Lima } \\
\text { (BAND, 2017) }\end{array}$ & $\begin{array}{l}\text { Escola pública em São Paulo ensina latim e grego para alunos do } \\
\text { fundamental (...) uma escola pública de São Paulo resolveu apostar nas } \\
\text { duas línguas milenares para trazer cultura aos estudantes. }\end{array}$ \\
\hline $\begin{array}{l}\text { Plataforma Latinitas - } \\
\text { UFBA e USP (UFBA, 2015) }\end{array}$ & $\begin{array}{l}\text { A plataforma Latinitas (...) será adotada a partir de } 2016 \text { pela USP. (...) A } \\
\text { Latinitas é uma plataforma online de ensino e aprendizagem de latim } \\
\text { desenvolvida na UFBA (...). Atualmente, o material também está sendo } \\
\text { aplicado em outras instituições na Bahia e em outros estados. }\end{array}$ \\
\hline $\begin{array}{l}\text { UNESP - Araraquara } \\
\text { (PRADO, 2014) }\end{array}$ & $\begin{array}{l}\text { No Brasil e em particular na Unesp de Araraquara, o ensino de latim conta } \\
\text { já há décadas (...) de pesquisa e experimentação do método desenvolvido } \\
\text { na FCL-Unesp de Araraquara. }\end{array}$ \\
\hline Unicamp (FORTES, 2013) & Trabalhos desenvolvidos no Grupo de Pesquisa sobre Ensino de Latim (...). \\
\hline $\begin{array}{l}\text { Colégio Pedro II (SOUZA E } \\
\text { SOUZA, 2012) }\end{array}$ & 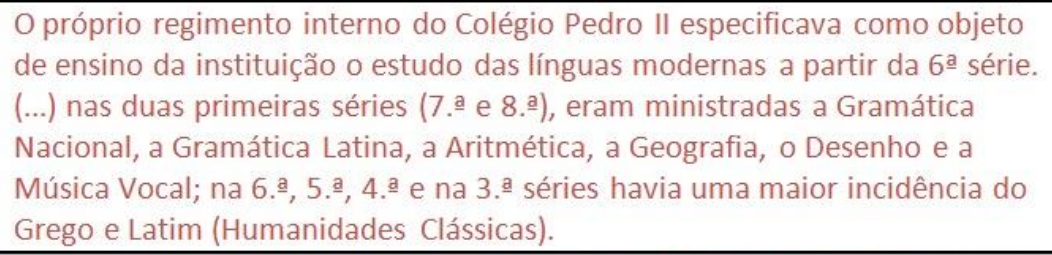 \\
\hline Alemanha (DW, 2012) & $\begin{array}{l}\text { Latim volta a ser popular nas escolas e universidades da Alemanha (...) é o } \\
\text { terceiro idioma estrangeiro mais estudado nas escolas alemãs, atrás do } \\
\text { inglês e do francês. (...) Cerca de } 800 \text { mil jovens alemães aprendem latim. }\end{array}$ \\
\hline $\begin{array}{l}\text { Plataforma Omnia - } \\
\text { UFRGS (UFRGS, 2012) }\end{array}$ & $\begin{array}{l}\text { OMNIA foi criado para divulgar os projetos do Setor de Latim do Instituto } \\
\text { de Letras da Universidade Federal do Rio Grande do Sul. }\end{array}$ \\
\hline
\end{tabular}

Fonte: Pesquisa bibliográfica realizada pelas autoras.

No ensino de Latim, métodos inovadores (em confronto à perspectiva tradicional) têm sido aplicados na prática e analisados em diferentes estudos (CORREA, 2018; ALVES et al., 2017; RIBEIRO, 2015). A esse propósito, cabe destacar a adaptação de métodos (inclusive com o uso de tecnologias atuais) para reduzir-se a distância cultural entre essa língua antiga e a realidade dos estudantes. 
Quadro 4 - Análises metodológicas sobre o ensino de Latim

\begin{tabular}{|c|c|}
\hline Pesquisa & Destaques da análise metodológica \\
\hline $\begin{array}{l}\text { O latim e o grego } \\
\text { em uma EMEF } \\
\text { (CORREA, 2018) }\end{array}$ & $\begin{array}{l}\text { O foco do Projeto Minimus é o ensino da língua grega e latina por meio de } \\
\text { materiais didáticos que, ao mesmo tempo, introduzem os alunos a vários } \\
\text { aspectos da cultura clássica: mitologia, história, política, teatro, poesia, música, } \\
\text { arte e arquitetura. }\end{array}$ \\
\hline $\begin{array}{l}\text { Reflexão sobre as } \\
\text { experiências e } \\
\text { dificuldades do } \\
\text { ensino da Língua } \\
\text { Latina na } \\
\text { Monitoria (ALVES } \\
\text { et al., 2017) }\end{array}$ & $\begin{array}{l}\text { Os objetivos da monitoria [de Língua Latina I] são: inserir alunos na prática } \\
\text { docente, reduzira reprovação e a evasão na disciplina, entender suas causas e } \\
\text { produzir uma reflexão sobre as dificuldades dos alunos no processo de } \\
\text { aprendizagem. Problemas vão desde a forma de ensino da língua, às questões } \\
\text { sociais, que afetam a vida dos alunos, causam dificuldades na aprendizagem e } \\
\text { fazem com que o componente seja considerado "difícil". (...) Desinteresse, } \\
\text { desconhecimento da importância da língua, base precária no ensino } \\
\text { fundamental, conteúdo pouco atraente (...) }\end{array}$ \\
\hline $\begin{array}{l}\text { Agoniza no Brasil } \\
\text { o Ensino do Latim } \\
\text { (RIBEIRO, 2015) } \\
\end{array}$ & $\begin{array}{l}\text { Objetiva-se (...) sugerir o referencial teórico ora utilizado a leitores interessados } \\
\text { pelo tema. Comenta-se sobre a rejeição recorrente de muitos a esse estudo em } \\
\text { razão de uma metodologia de ensino arcaica e descontextualizada. }\end{array}$ \\
\hline $\begin{array}{l}\text { Plataforma } \\
\text { Latinitas será } \\
\text { adotada em cursos } \\
\text { da USP } \\
\text { (UFBA, 2015) }\end{array}$ & $\begin{array}{l}\text { A plataforma Latinitas - método de ensino de latim desenvolvido pela UFBA (...) } \\
\text { se estrutura em três pilares: oferecer um ambiente virtual de aprendizagem } \\
\text { complementar à abordagem da sala de aula, que ocorre através do material } \\
\text { impresso; oferecer recursos complementares à aprendizagem em outras mídias; } \\
\text { e reconhecer as atuais formas de aprender e de interagir dos estudantes. }\end{array}$ \\
\hline $\begin{array}{l}\text { O ensino de língua } \\
\text { latina no Brasil: } \\
\text { percursose } \\
\text { perspectivas } \\
\text { (LEITE e CASTRO, } \\
2014 \text { ) }\end{array}$ & $\begin{array}{l}\text { Este trabalho procurou traçar um panorama do ensino de línguas clássicas, em } \\
\text { especial da língua latina no Brasil, (...) buscando compreender os movimentos } \\
\text { que levaram à situação atual, em que a língua latina ocupa espaço mínimo nos } \\
\text { currículos universitários, em geral apenas dos cursos de Letras. Em seguida, } \\
\text { procurou-se esboçar o quadro atual dos debates na área do ensino de língua } \\
\text { latina na universidade brasileira, apontando-se os principais desafios } \\
\text { enfrentados. }\end{array}$ \\
\hline $\begin{array}{l}\text { Ensino de latim e } \\
\text { educação } \\
\text { linguística: } \\
\text { reflexão sobre } \\
\text { materiais método } \\
\text { (PRADO, 2014) }\end{array}$ & $\begin{array}{l}\text { Revisões críticas de métodos de ensino de línguas antigas (...) [são] frequentes, } \\
\text { (...) [para] ensino de latim, cujos métodos mais recentes propõem atualizações } \\
\text { formais e de estratégias didáticas, como (...) plataformas eletrônicas (...), e (...) } \\
\text { calcados na abordagem comunicativa do idioma. (...) este texto discute alguns } \\
\text { dos instrumentos (...) para um método de ensino de latim apoiado na formação } \\
\text { linguística (...) formulação de exercícios e de um dicionário adequados (...). }\end{array}$ \\
\hline $\begin{array}{l}\text { O ensino de latim } \\
\text { centrado no uso } \\
\text { da língua e na } \\
\text { aquisição de } \\
\text { competências } \\
\text { (FORTES, 2013) } \\
\end{array}$ & $\begin{array}{l}\text { O ensino de línguas clássicas no Brasil tem suscitado, nos últimos anos, a } \\
\text { produção, tradução eadaptação de métodos de ensino de latim (...) propomos } \\
\text { (...) confrontar a perspectiva tradicional do ensino dessa língua, assentada sobre } \\
\text { a cobertura de conteúdos gramaticais, a uma perspectiva fundamentada na } \\
\text { aquisição de competências de linguagem (...), com vistas ao domínio do uso } \\
\text { efetivo da língua e, sobretudo, à proficiência na leitura de textos autênticos (...). }\end{array}$ \\
\hline $\begin{array}{l}\text { O Ensino do Latim } \\
\text { no Brasil: } \\
\text { objetivos, método, } \\
\text { tradicão } \\
\text { (HECK, 2013) }\end{array}$ & $\begin{array}{l}\text { (...) adentra-se na questão do método que servirá como caminho para se } \\
\text { alcançar os objetivos traçados no ensino da língua latina. (...) tecer } \\
\text { considerações sobre a possibilidade de resgate do ensino do latim como } \\
\text { disciplina de humanidade (laica) no Ensino Fundamental e Médio, para } \\
\text { adestramento decapacidades etalentos, e, no Ensino Superior, para a formação } \\
\text { de professores competentes. }\end{array}$ \\
\hline
\end{tabular}

Fonte: Pesquisa bibliográfica realizada pelas autoras.

A questão da atualização dos métodos de ensino e das plataformas eletrônicas ou dos ambientes virtuais de aprendizagem é importante para evitar-se a "rejeição recorrente de muitos a esse estudo [o do latim] em razão de uma metodologia de ensino arcaica e descontextualizada" (RIBEIRO, 2015, p. 8). Nesse sentido, “a tradução para o latim de obras best-sellers, como Harry Potter, [...] se tornam um fator de interesse por jovens para seu estudo" (NASCIMENTO, 2012, p. 22). A 
esse respeito, vale ressaltar a abordagem do curso de Latim do programa de Extensão da UFRGS

(NELE - Núcleo de Ensino de Línguas em Extensão) (UFRGS, 2021; COSTA, 2019).

\begin{abstract}
Como aprender latim de uma forma agradável? [...] Através da leitura e audição de textos inicialmente facilitados, o vocabulário e as regras gramaticais podem ser apreendidos naturalmente. É necessário, ainda, fazer muitos exercícios. Atividades lúdicas e envolventes também devem fazer parte desse pacote. Afinal, tempora mutantur, nos et mutamur in illis. Podemos e devemos, portanto, explorar recursos modernos: CD-ROM, ambiente virtual, exercícios interativos, que aproximem o mundo clássico da realidade atual no que diz respeito ao acesso à informação que têm nossos estudantes. Os alunos devem se sentir motivados a estudar com prazer, interesse e entusiasmo. (UFRGS, 2021, p. 1).
\end{abstract}

Uma enquete informal sobre tais métodos com uso de filmes teve respostas positivas, como atesta o quadro 5, a seguir:

Quadro 5 - Avaliação dos métodos do NELE-UFRGS

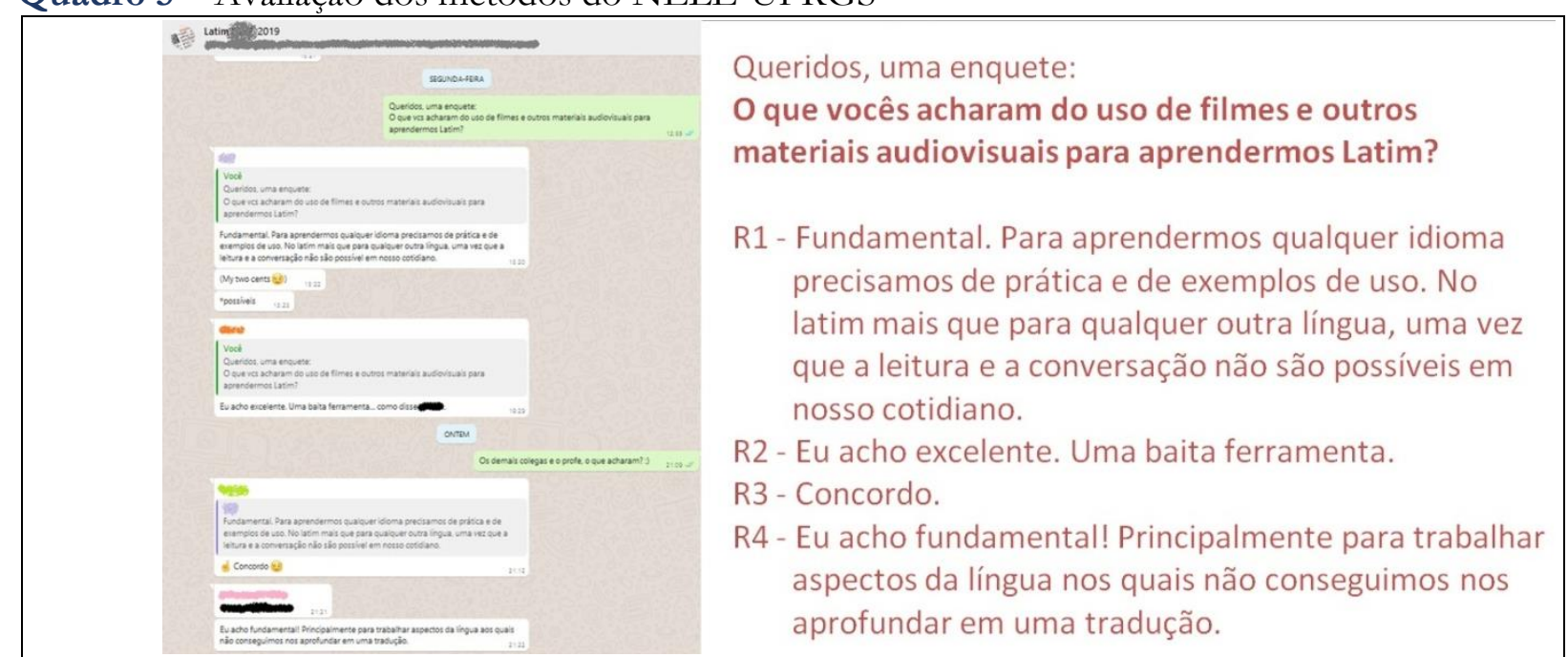

Fonte: Enquete informal realizada pelas autoras.

Especificamente em relação ao uso de filmes no ensino de Latim, foco desta pesquisa, uma breve revisão filmográfica apontou diversas obras, disponíveis em uma plataforma de compartilhamento de vídeos ( $c f$. quadro 6). 
Dossiê Educação e Cinema: atos formativos

Quadro 6 - Alguns filmes que apresentam trechos falados em latim

\begin{tabular}{|l|l|l|}
\hline Filme (ano) & Identificação da Cena & Link (Ctrl+clique) \\
\hline Bárbaros (Série) (2020) & Anúncio do novo governo e impostos & ojC-zTXSAsY \\
\hline Il Primo Re (2019) & Discurso de Remo & TxhDH463sBc \\
\hline Os Dois Papas (2019) & Discurso de Bento XVI & 8m1A05vqa1M \\
\hline Anjos e Demônios (2009) & Fechamento da porta do conclave & D9AOyT2BDr4\&t=94s \\
\hline O Código da Vinci (2006) & Autoflagelo de Silas & d7pioagkX5k \\
\hline A Paixão de Cristo (2004) & Soldados debochando de Jesus & K-6TPIo1F9o \\
\hline Coração Valente (1995) & Conversa de Wallace e Isabela & -7pX090gzg8 \\
\hline Coração Valente (1995) & Oração do funeral & C68y8pSX3FI \\
\hline Tombstone (1993) & Provocação no bar & LS5NrTfdIU4 \\
\hline Sociedade dos Poetas Mortos(1990) & Carpe Diem & g5HZ1Uk5f0E \\
\hline O Nome da Rosa (1986) & Canto gregoriano & khPpQg8S2-w \\
\hline A Vidla de Brian (1979) & Pichação & hKsZ4wb67vI \\
\hline Asterix - Os 12 Trabalhos (1976) & Gladiadores saudando César & iVBZCCQJUE \\
\hline O Exorcista (1974) & Exorcismo & kH8XhOPv9GA \\
\hline Destiny of Rome (1972) & Discurso de Marco Antônio & \\
\hline
\end{tabular}

Fonte: Pesquisa filmográfica realizada pelas autoras.

\section{Método}

Esta investigação pode ser caracterizada como qualitativa e exploratória, além de descritiva. Para a coleta de dados, usou-se o método levantamento filmográfico (MALANOVICZ, 2020; ECA-USP, 2019), além da pesquisa bibliográfica e filmográfica apresentada na seção 2 do presente artigo.

As fontes de dados são os sete livros da saga Harry Potter (ROWLING, 1997, 1998, 1999, 2000, 2003, 2005, 2007) e os oito filmes que consistem em adaptações cinematográficas dos referidos livros (COLUMBUS, 2001, 2002; CUARÓN, 2004; NEWELL, 2005; YATES, 2007, 2009, 2010, 2011). Quanto ao protocolo de coleta de dados nessas fontes, este previu apenas o título do livro/filme, os nomes dos feitiços e a página (livro) / minutagem (filme) em que aparece ( $c f$. quadro 7):

Quadro 7 - Protocolo de coleta de dados em livros e filmes

(a)

\begin{tabular}{|l|l|l|}
\hline Livro & Página & Feitiço \\
\hline & & \\
\hline & & \\
\hline & & \\
\hline
\end{tabular}

(b)

\begin{tabular}{|l|l|l|}
\hline Filme & Minutagem & Feitiço \\
\hline & & \\
\hline & & \\
\hline & & \\
\hline
\end{tabular}

$\mathrm{Na}$ análise dos dados coletados, foi aplicada a técnica Análise de Conteúdo (BARDIN, 2004). Os resultados da pré-análise foram apresentados na forma de tabelas e de nuvem de palavras (www.wordclouds.com), para facilitar a visão global dos dados.

A análise de dados explorou os feitiços que utilizam expressões latinas, confrontando-as com os temas da gramática latina abordados em obras técnicas tanto tradicionais quanto inovado- 
ras. Dentre as obras tradicionais, constam as de Almeida (2011) e Rónai (1980). Dentre as inovadoras, encontram-se as de Costa (2019) e o Victionarium (2020). Também foram referenciados blogs, sites e canais que tratam do latim nos feitiços da série Harry Potter, como as seguintes páginas: Potterish (2009, 2010), Wizarding (2017), Caldeirão (2019) e Aficionados (2020).

No que concerne à discussão dos resultados, esta buscou investigar a viabilidade do uso didático de feitiços da referida série selecionados neste extenso levantamento. Para tanto, discutiuse o esboço de uma atividade didática e os métodos que usam filmes na educação.

\section{Resultados}

Esta seção apresenta os resultados da etapa aplicada do trabalho (cf. dados brutos disponíveis no Apêndice A). A visualização de dados em nuvem de palavras evidencia, em tamanhos maiores, as ocorrências mais frequentes dos termos identificados na análise de conteúdo (por exemplo, Expelliarmus 24 ocorrências; Estupefaça, 17 ocorrências; Expecto Patronum, 13 ocorrências), como demonstra a figura 1 , a seguir.

Figura 1 - Nuvem de feitiços (wordclouds.com) dos livros (a) e dos filmes (b)
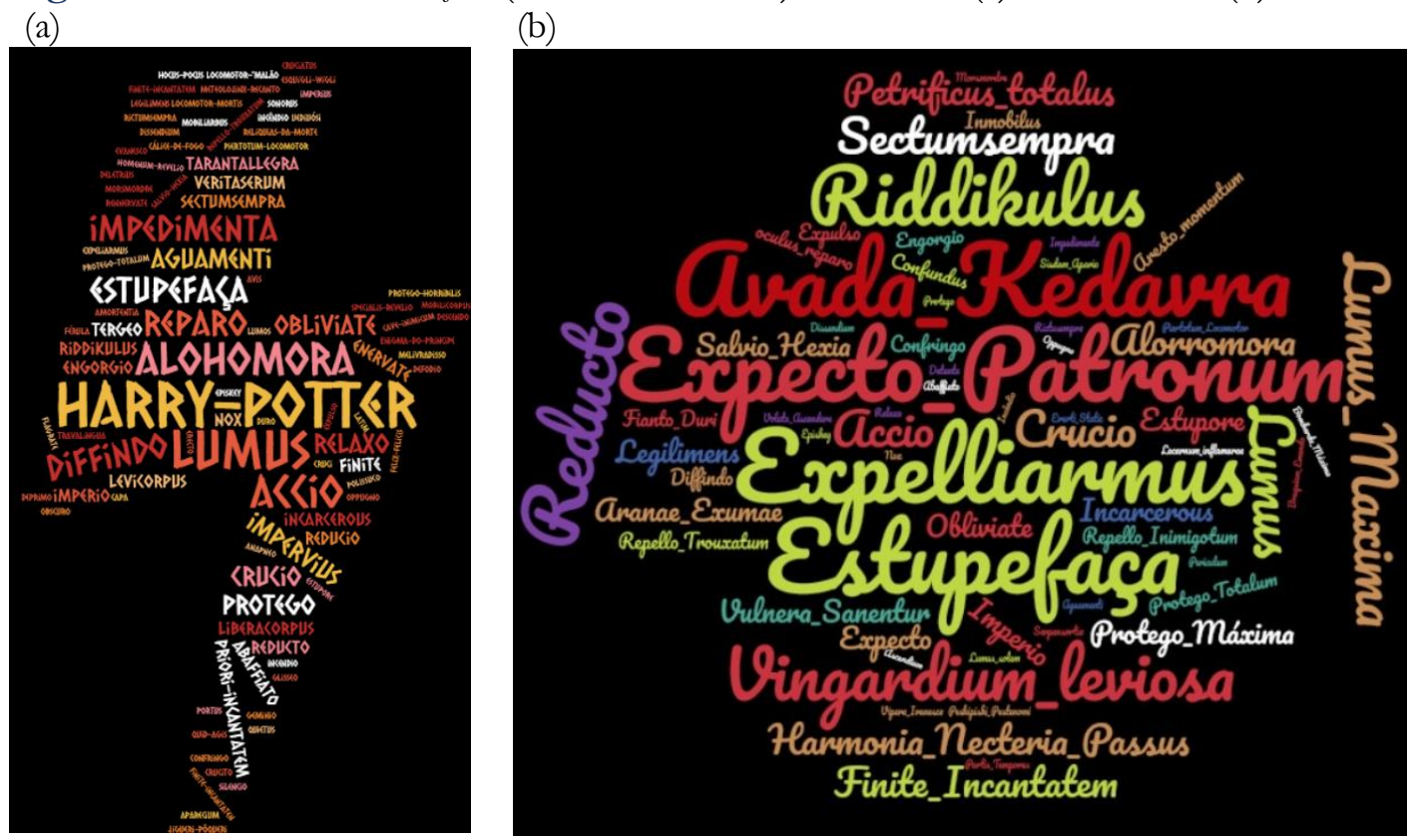

Fonte: As autoras

Ao elencar-se e analisar-se as cenas de filmes que mostram feitiços ( $c f$. Apêndice B), foram selecionados os feitiços cujos nomes têm origem no latim, assim como foram adicionados a imagem e o link para a cena em que o feitiço é proferido. Além disso, indicaram-se a origem latina dos nomes dos feitiços e o tema gramatical que pode ser estudado a partir desses nomes.

Como comentário inicial, vale observar que os feitiços Alohomora e Avada Kedavra não têm origem no latim. Cabe igualmente pontuar que não foram foco desta pesquisa outras expressões 
de origem latina presentes nos filmes da saga Harry Potter, tais como nomes de personagens (Remo Lupin, Severus, Dolores), poções (veritaserum) e o próprio lema da Escola de Magia e Bruxaria de Hogwarts (“Draco Dormiens Numquam Titillandus”). Faz-se importante registrar também que há feitiços que parecem derivados do latim, mas não o são:

[...] apesar de parecerem Latim, muitos dos nomes são puro enfeite. [...] sufixos como "ium” [...]. "Trata-se de um 'latinorum', isto é, parece latim, soa como latim, mas não é propriamente latim [...]”, afirma Alexandre Hasegawa, professor de Latim na USP [...] (EXAME, 2016, p. 1, aspas e itálicos do original).

Esses casos de "latinorum" podem ser usados para melhor fixação de cada conteúdo da língua latina a ser trabalhado pelo professor, a partir da demonstração negativa de cada construção gramatical utilizada nos nomes dos feitiços. Uma lição pode talvez ser mais bem assimilada quando o professor apresenta aos alunos exemplos de como é e de como não é, ou seja, apresenta o correto e o incorreto, para contrastar.

Os feitiços aqui analisados são expressos geralmente por um verbo transitivo seguido de ou antecedido por um objeto direto (por exemplo, expecto patronum, aresto momentum, vipera evanesco, oculus reparo, aperio cistam, alarte ascendere) e podem ser utilizados no estudo do caso acusativo, ao comparar-se, a título de ilustração, as formas nominativas patronus e oculus com suas formas acusativas patronum e oculum ou oculos.

Outra construção que nomeia feitiços combina substantivo e adjetivo, os quais devem concordar em gênero, número e caso (por exemplo, bombarda maxima, lumen maxima), podendo ser mobilizados no estudo da flexão dos adjetivos.

Outra construção combina substantivo e genitivo (por exemplo, locomotor mortis, partis temporis). Há, também, construções só com o verbo conjugado no presente (por exemplo, [ego] confringo, [ego] crucio, [vos] obliviate). Há, igualmente, construções com apenas o substantivo (por exemplo, nox, impedimenta, periculum) ou o adjetivo (por exemplo, riddikulus - um "latinorum"), que podem ser produtivas no ensino de etimologia, ao resgatarem-se palavras de origem ou inspiração latina que se assemelham a vocábulos da língua portuguesa.

O caso dativo tem como exemplo a maldição imperio; o ablativo, o feitiço bracchium emendo; o vocativo, a conjuração da Marca da Morte (morsmordre); o particípio, os feitiços incarcerous e reducto; o imperativo, o feitiço obliviate; o passado, o feitiço legilimens (esse feitiço também pode ser útil para o ensino dos processos de formação de palavras). Como exemplo de advérbios, pode ser debatido o feitiço sectumsempra; de prefixos latinos, oppugno; de conjuntivo, vulnera sanentur.

As cenas listadas no Apêndice B são trechos de filmes que podem ser utilizados como formas de despertar o interesse dos estudantes, no início de uma aula ou no início da exposição 
sobre um tema específico. São formas inovadoras de ilustrar e memorizar o conteúdo gramatical, devido ao auxílio audiovisual para a lembrança das cenas e dos feitiços que nelas aparecem.

Uma proposta de possíveis usos, no ensino de Latim, de cenas de feitiços dos filmes da série Harry Potter foi, assim, apresentada nesta pesquisa. Tal proposta pode ser usada em cursos de graduação e pós-graduação, cursos livres, Ensinos Médio e Fundamental, na modalidade tanto presencial quanto on-line ou a distância. Espera-se que a ideia aqui sugerida ofereça aos alunos uma contribuição para o seu processo de aprendizagem.

\section{Discussão}

Esta seção apresenta uma discussão crítica dos benefícios e das limitações da proposta de uso didático das cenas de filmes da série Harry Potter para o aprendizado de Latim. A exemplo de outras obras de pesquisa, os métodos inovadores no ensino de Latim são enfocados em oposição aos tradicionais (CORREA, 2018; ALVES et al., 2017; RIBEIRO, 2015), e a proposta apresenta na presente pesquisa usa recursos da realidade dos estudantes.

A análise de dados realizada nesta pesquisa mostrou que os assuntos gramaticais da língua latina que podem ser abordados a partir de cenas de filmes da série Harry Potter incluem: palavras latinas que deram origem a palavras da língua portuguesa; casos nominativo, acusativo, genitivo, dativo, ablativo, vocativo; flexão de adjetivos em gênero, número e caso; concordância nominal de adjetivo com substantivo; advérbios, verbos de diferentes conjugações, diferentes pessoas (ego, vos) e diferentes tempos verbais (presente, passado, futuro); formas verbais menos usuais, como particípio passado, imperativo e conjuntivo; e a variedade de pronúncias do latim.

Além disso, há, nos feitiços, expressões inspiradas no latim, mas que não fazem parte da língua, devido a alguma discrepância na grafia. A exploração dos erros (ou casos de livre e consciente inspiração no latim) presentes nas cenas pode facilitar a aprendizagem da língua latina, por permitir contrastar exemplos gramaticalmente corretos e incorretos, que proporcionam melhor apreensão do conteúdo pelos alunos.

Dentre os diversos benefícios do uso de filmes no ensino, podem ser relembrados fatores como os seguintes: o estímulos aos sentidos (LOPES; PEREIRA; LAMMEL, 2019); ampliação da visão do aluno (BERK; ROCHA, 2019); maior perenidade de resultados, devido à memorização propiciada pelo audiovisual (SOUZA; SILVA, 2018); aproximação do estudante em relação ao mundo figurável e não só a ideias abstratas (BAHIA; SILVA, 2017); e atração da atenção dos estudantes (SILVA et al., 2015).

Vários desses benefícios foram constatados em pesquisas recentes em escolas, em disciplinas como Ciências (BERK; ROCHA, 2019; CARVALHO, 2017), Língua Portuguesa (SILVA; 
OBANDO, 2019; CARVALHO, 2017), Química (CAMPOS et al., 2019), Geografia (NEZ; LEITE, 2018), Artes (RODRIGUES; COMERLATO, 2018), Matemática (CARVALHO, 2017), Sociologia (ANGREWSKI, 2015).

Em alguns desses trabalhos citados, são relatadas dificuldades estruturais para o uso do cinema nas escolas, que não podem ser excluídas da presente discussão. Frente a tal realidade, a exibição de filmes na íntegra usando-se aparelhos de DVD é exceção. No entanto, o uso de trechos de filmes que estão disponíveis na internet em uma plataforma de compartilhamento de vídeos parece simplificar o acesso de professores e estudantes às cenas de filmes, desde que disponham de um celular e de acesso à internet. O extenso levantamento aqui realizado pode oferecer uma contribuição nesse sentido, pois apresenta um rol de cenas específicas de feitiços, foco desta pesquisa, com links para a referida plataforma.

Os recursos apresentados nesta investigação podem oferecer alguma contribuição no sentido de mitigar problemas relatados no que diz respeito à aprendizagem do Latim (ALVES et al., 2017), como dificuldades ou desinteresse pelo conteúdo, considerado pouco atraente. A rejeição ao estudo do latim pode ser convertida em atração, devido à atualidade das obras e à forma audiovisual de apresentação delas. As cenas de filmes podem ser o disparador do início da exposição de cada tema, seja sobre gramática, seja sobre literatura e cultura romanas.

Os filmes de Harry Potter reaqueceram os debates recentemente na mídia e na academia (SUPERPROF, 2019; GAZETA, 2019; CORREA, 2018; OLIVEIRA, 2017; BAND, 2017; EXAME, 2016; RIBEIRO, 2015; AMARANTE SANTOS SOBRINHO, 2014; POTTERISH, 2009). Como visto na seção 2 deste artigo, há inúmeros argumentos sobre a importância do ensino de Latim, de modo que algumas escolas e universidades no Brasil o oferecem. Pode-se avaliar que o uso aqui proposto dos trechos de filmes pode ser útil em qualquer nível educacional, sejam cursos livres, extensão, graduação, pós-graduação, Ensinos Médio ou Fundamental, presenciais ou a distância.

Talvez esta pesquisa contextualizada nas produções fílmicas da série Harry Potter tenha a possibilidade de problematizar e questionar uma realidade social - no caso, a ausência do Latim no ensino - ou, pelo menos, despertar o interesse dos estudantes por questões da antiguidade clássica, como na escola Amorim Lima (GAZETA, 2019; CORREA, 2018; BAND, 2017; AMORIM, 2013). A atração pelo conteúdo pode render mais interesse dos estudantes no seu processo de aprendizagem, o que já é um expressivo benefício.

\section{Conclusão}


Esta pesquisa alcançou seu objetivo de identificar as cenas de feitiços dos filmes da saga Harry Potter que podem ser utilizadas como apoio no ensino de Latim. Foram identificadas 221 ocorrências de feitiços nos filmes, e, evitando-se repetições, foram selecionadas 48 cenas de feitiços, fornecendo-se o link para sua apreciação em uma plataforma de compartilhamento de vídeos na internet. Os feitiços encenados foram analisados em relação ao tópico de latim que poderiam ilustrar, indicando-se cenas de apoio para casos, etimologia, tempos verbais, concordâncias e classes gramaticais.

Pode-se concluir que a proposta de uso dessas cenas selecionadas tem o potencial de oferecer como contribuição os diversos benefícios da aplicação do cinema no ensino, como ilustração, atratividade, atualidade, memorização, dentre outros, além de despertar o interesse dos estudantes pelo seu próprio processo de aprendizagem. Assim, entende-se o uso de trechos de filmes como uma estratégia didática que pode ser empregada para aproximar o cotidiano do aluno dos conteúdos curriculares.

Devem ser mencionadas como limitações desta pesquisa a delimitação do foco aos feitiços, que não representam diálogos mais complexos. Trabalhos de pesquisa futuros podem envolver, por exemplo, o aprofundamento nos diálogos em língua latina presentes nos filmes de Asterix ou na série televisiva Bárbaros, bem como nos livros da série Harry Potter já traduzidos para o latim.

Concretiza-se, assim, a percepção da oportunidade de a série de filmes Harry Potter ser utilizada como alternativa às tradicionais aulas expositivas da "educação bancária” (FREIRE, 1970), pois tal iniciativa configura um modo de se ilustrarem variados temas gramaticais e linguísticos do latim, de maneira criativa, envolvente e divertida.

\section{Referências}

AFICIONADOS. 53 feitiços do universo Harry Potter explicados! por Sabryna Esmeraldo. 17 abr. 2020. Disponível em: https://www.aficionados.com.br/feiticos-harry-potter-traduzidos-explicados/. Acesso em: 31 mar. 2021.

ALMEIDA, N. M. Gramática Latina: curso único e completo. 30. ed. São Paulo: Saraiva, 2011.

ALVES, A. B.; PEREIRA, J. D. de P.; SOUZA, L. C. T. Hoje vamos estudar Latim: uma reflexão sobre as experiências e dificuldades do ensino da Língua Latina na Monitoria. COIPESU Colóquio Internacional de Pesquisas em Educação Superior, 4., Anais... 4-6 set. 2017, Eixo 5: Educação, Universidade e Saberes. UFPB - Universidade Federal da Paraíba. Disponível em: https://www.coipesu.com.br/anais. Acesso em: 31 mar. 2021.

AMARANTE SANTOS SOBRINHO, J. Vocêtem notícia do latim? Prêmio Capes de Teses 2014 Letras e Linguística. 11 dez. 2014.1 vídeo (22min57s). Disponível em: https:/ /www.youtube.com/watch?v=TN_QljVp4Eo. Acesso em: 31 mar. 2021. 
AMORIM LIMA, Escola Municipal de Ensino Fundamental Desembargador. Festa da Cultura 2013: encontro com a nossa história. set. 2013. Disponível em: https:/ /amorimlima.org.br/2013/09/festa-da-cultura-2013-encontro-com-a-nossa-historia/. Acesso em: 07 mai. 2021.

ANGREWSKI, E. Utilização do cinema no ensino de Sociologia: o que os professores têm a dizer? Congresso Nacional de Educaşão (EDUCERE), Curitiba, 12, p. 26-29, out. 2015. Disponível em: https://educere.bruc.com.br/arquivo/pdf2015/16742_9708.pdf. Acesso em: 18 set. 2020.

BACICH, L. Metodologias ativas para uma educação inovadora: uma abordagem teórico-prática. Porto Alegre: Penso, 2017.

BAHIA, A.; SILVA, A. Modelo de produção de vídeo didático para EaD. Revista Renote, n. 15, v. 1, p. 1-10, 2017.

BAND News TV. Escola pública em São Paulo ensina latim e grego para alunos do fundamental. 23 nov. 2017. Disponível em: https://videos.band.uol.com.br/16356360/escola-publica-em-sao-pauloensina-latim-e-grego-para-alunos-do-fundamental.html. Acesso em: 07 mai. 2021.

BARDIN, L. Análise de conteúdo. 3. ed. Rio de Janeiro: Edições 70, 2004.

BERK, A.; ROCHA, M. O uso de recursos audiovisuais no ensino de Ciências. Contexto \& Educação, n. 34, v. 107, jan.-abr. 2019. Disponível em: https://www.revistas.unijui.edu.br/index.php/contextoeducacao/article/view/7430. Acesso em: 31 mar. 2021.

CALDEIRÃO FURADO. O significado dos feitiços em Harry Potter! 8 dez. 2019. 1 vídeo (19min02s). Disponível em: https://www.youtube.com/watch?v=LxtK0usLXbY. Acesso em: 31 mar. 2021.

CAMPOS, R. M.; TAMIASSO-MARTINHON, P.; SOUSA, C.; SOUZA, E. T.; ROCHA, A. S. Uso de filmes no ensino de radioatividade: uma estratégia motivadora para aulas do nível médio. Scientia Naturalis, Rio Branco, v. 1, n. 3, p. 193-208, 2019. Disponível em: https:/ /periodicos.ufac.br/index.php/SciNat/article/view/2555. Acesso em: 18 set. 2020.

CARVALHO, A. C. de S. Importância da inserção de filmes e vídeos na prática Docente. Pedagogia - Universidade Federal de Juiz de Fora (UFJF), 2017. Disponível em:

https://www.ufff.br/pedagogia/files/2017/12/Import\%c3\%a2ncia-da-Inser\%c3\%a7\%c3\%a3ode-filmes-e-v $\%$ c 3\%addeos-na-pr $\%$ c3\%a1tica-docente-no-Ensino-Findamental-I.pdf. Acesso em: 18 set. 2020 .

COLUMBUS, Chris. Harry Potter e a Pedra Filosofal (filme). EUA. Warner Bros, 2001. 2h39min.

COLUMBUS, Chris. Harry Potter e a Câmara Secreta (filme). EUA. Warner Bros, 2002. 2h54min.

CORRÊA, P. da C. O latim e o grego em uma escola municipal de Ensino Fundamental. Estudos Avançados, São Paulo, v. 32, n. 93, p. 121-125, ago. 2018. Disponível em: https://www.scielo.br/scielo.php?script $=$ sci_arttext\&pid $=$ S0103-40142018000200121\&lng=en\&nrm $=$ iso. Acesso em: 27 mar. 2021.

COSTA, L. N. Material de Aula do Curso de Latim do NELE-UFRGS. 2019. 103 p.

CUARÓN, Alfonso. Harry Potter e o Prisioneiro de Aq̌aban (filme). EUA. Warner Bros, 2004. $2 \mathrm{~h} 22 \mathrm{~min}$. 
DOMINGUES, N. O papel do vídeo nas aulas multimodais de Matemática Aplicada: uma análise do ponto de vista dos alunos. 2014. 128 f. Dissertação (Mestrado em Educação Matemática) - Universidade Estadual Paulista Júlio de Mesquita Filho, Rio Claro/SP, 2014. Disponível em: http://www.rc.unesp.br/gpimem/downloads/dissertacoes/domingues_ns_me_rcla.pdf Acesso em: 31 mar. 2021.

DW - Deutsche Welle. Latim volta a ser popular nas escolas e universidades da Alemanha. Por Janine Albrecht, 19 set. 2012. Disponível em:

https://www.dw.com/pt-br/latim-volta-a-ser-popular-nas-escolas-e-universidades-da-alemanha/a-16246030. Acesso em: 31 mar. 2021.

ECA-USP. História e Audiovisual: Circularidades e Formas de Comunicação. Anais do 5o. Colóquio Internacional de Cinema e História, UFPR, Curitiba, PR, p. 3-6, dez. 2019. Disponível em: http:/ / historiaeaudiovisual.weebly.com/iv-coloacutequio.html. Acesso em: 18 set. 2020.

EL PAÍS. Ler, escrever, contar, respeitar: França volta ao básico na educação. Por Marc Bassets, Paris, 23 nov. 2018. Disponível em: https://brasil.elpais.com/brasil/2018/11/17/actualidad/1542486423_832733.html. Acesso em: 31 mar. 2021.

EXAME. O que significam, em latim, os feitiços de Harry Potter. Por Felipe Germano, 08 dez. 2016. Disponível em: https:/ / exame.com/casual/o-que-significam-em-latim-os-feiticos-de-harry-potter/. Acesso em: 31 mar. 2021.

FORTES, F. da S. O ensino de latim centrado no uso da língua e na aquisição de competências. PhaoS, v.13, 2013, pp.7-21. Disponível em: https://revistas.iel.unicamp.br/index.php/phaos/article/view/4589. Acesso em: 31 mar. 2021.

FREIRE, P. Pedagogia do oprimido. Rio de Janeiro: Paz e Terra, 1970.

FUNDAÇÃO TORINO. Fundação Torino: Escola Internacional. 2018. Disponível em: http://www.fundacaotorino.com.br/ei/. Acesso em: 31 mar. 2021.

GAZETA DO POVO. Iniciativas em escolas no Brasil mostram que o latim não está morto. Por Gabriel de Arruda Castro, 14 set. 2019. Disponível em: https://www.gazetadopovo.com.br/educacao/iniciativas-em-escolas-no-brasil-mostram-que-o-latim-nao-esta-morto/. Acesso em: 31 mar. 2021.

HECK, M. R. D. O ensino de latim no Brasil: objetivos, métodos e tradição. 2013. 36 f. Trabalho de Conclusão de Curso (Licenciatura em Letras) - Universidade Federal do Rio Grande do Sul, Porto Alegre, 2013. Disponível em: https://lume.ufrgs.br/bitstream/handle/10183/94996/000916477.pdfsequence=1\&isAllowed=y. Acesso em: 31 mar. 2021.

KÜHL, M. Comentário. 2020. O significado dos feitiços em Harry Potter. 8 dez. 2019. Disponível em: https://www.youtube.com/watch?v=LxtK0usLXbY. Acesso em: 07 mai. 2021.

LEITE, L. R.; CASTRO, M. B. e. O ensino de língua latina no Brasil: percursos e perspectivas. Classica - Revista Brasileira de Estudos Clássicos, v.27, n. 2, 2014, p.53-77. Disponível em: https:/ / revista.classica.org.br/classica/article/view/226. Acesso em: 31 mar. 2021. 
LOPES, T.; PEREIRA, F.; LAMMEL, I. Gestão da Produção de Recursos Educacionais em Áudio e Vídeo. EaD Em Foco, n. 9, v. 1, 2019. Disponível em: https://doi.org/10.18264/eadf.v9i1.746. Acesso em: 31 mar. 2021.

MALANOVICZ, A. V. Direito Romano in Streaming. Romanitas, v. 16, n. 2, 2020. Disponível em: https://portaldepublicacoes.ufes.br/romanitas/issue/view/1150. Acesso em: 18 set. 2020.

NASCIMENTO, L. F. "Flor do Lácio: o Latim. O que quer, o que pode esta lingua?”. 2012. 50 f. Trabalho de Conclusão de Curso (Licenciatura em Letras) - Universidade do Estado da Bahia, Conceição do Coité, 2012. Disponível em: https://pt.slideshare.net/BPJCA/flor-do-lcio-o-latim-o-quequer-oque-pode-esta-lngua. Acesso em: 07 mai. 2021.

NEWELL, M. Harry Potter e o Cálice de Fogo (filme). EUA. Warner Bros, 2005. 2h27min.

NEZ, E.; LEITE, A. F. Levantamento de obras cinematográficas para utilização no ensino de Geografia. EDUCA - Revista Multidisciplinar em Educação, Porto Velho, v. 5, n. 10, p. 165-182, jan.abr., 2018. Disponível em: https://www.periodicos.unir.br/\%20index.php/EDUCA/index. Acesso em: 18 set. 2020.

OLIVEIRA, J. M. O latim de Roma a Harry Potter. Congresso Internacional ABRALIC, 15o. Rio de Janeiro, p. 07-11, ago. 2017, Anais... UERJ, p. 2189-2195. Disponível em: http://www.abralic.org.br/anais/arquivos/2017_1522188781.pdf. Acesso em: 31 mar. 2021.

POTTERISH. Mágico Latim. Por Bruna Moreno. 8 out. 2010. Disponível em: http:/ / potterish.com/2010/10/magicolatim/. Acesso em: 31 mar. 2021.

POT'TERISH. Harry Potter e a volta do Latim: uma alternativa também para o Brasil. Por Vítor Ruwer Werle. 24 maio 2009. Disponível em: https:/ / potterish.com/hp-e-a-volta-do-latim-uma-alternativa-tambem-para-o-brasil/. Acesso em: 31 mar. 2021.

PRADO, J. B. T. Ensino de latim e educação linguística: reflexão sobre materiais e método. PhaoS, v. 14, 2014, p. 143-155. Disponível em: https://revistas.iel.unicamp.br/index.php/phaos/article/view/4640. Acesso em: 31 mar. 2021.

PRENSKY, M. Digital natives, digital immigrants. In: PRENSKY, Marc. On the horizon. Lincoln: MCB University Press, v. 9, n. 5, out. 2001. Disponível em: https://www.marcprensky.com/writing/Prensky $\% 20-\% 20$ Digital $\% 20$ Natives, $\% 20$ Digital $\% 20$ Immigrants $\% 20$ \%20Part1.pdf Acesso em: 31 mar. 2021.

RIBEIRO, D. H. P. Agoniza no Brasil o Ensino do Latim. Transformar - Revista do Centro de Iniciação Científica e Extensão (CENICE), n. 7, nov. 2015. p. 8-19. Disponível em: http://www.fsj.edu.br/transformar/index.php/transformar/article/view/21. Acesso em: 31 mar. 2021.

RODRIGUES, D.; COMERLATO, D. Oficina de Cinema na Escola: uma Nova Proposta Pedagógica. In: CANDIDO, Eliane; PEREIRA, Josias (Orgs.). São Léo em Cine: a escola construindo sonhos. São Leopoldo-RS: Editora ERD Filmes, 2018.

RÓNAI, P. Não perca o seu latim. 3. ed., rev. ampl. Rio de Janeiro: Nova Fronteira, 1980.

ROWLING, J. K. Harry Potter e a Pedra Filosofal. Rio de Janeiro, Rocco, 1997. 
ROWLING, J. K. Harry Potter e a Câmara Secreta. Rio de Janeiro, Rocco, 1998.

ROWLING, J. K. Harry Potter e o Prisioneiro de Azkaban. Rio de Janeiro, Rocco, 1999.

ROWLING, J. K. Harry Potter e o Cálice de Fogo. Rio de Janeiro, Rocco, 2000.

ROWLING, J. K. Harry Potter e a Ordem da Fênix. Rio de Janeiro, Rocco, 2003.

ROWLING, J. K. Harry Potter e o Enigma do Príncipe. Rio de Janeiro, Rocco, 2005.

ROWLING, J. K. Harry Potter e as Relíquias da Morte. Rio de Janeiro, Rocco, 2007.

SANTOS, S.; SANTOS, C. Da educação à comunicação: um mapeamento da utilização do vídeo online em universidades portuguesas. OBS*, v. 8, n. 3, p. 17-37, set. 2014. Disponível em: http://www.scielo.mec.pt/pdf/obs/v8n3/v8n3a02.pdf. Acesso em: 02 mai. 2020.

SILVA, J. A. Cinema e educação: o uso de filmes na escola. Revista Intersaberes, v. 9, n. 18, p. 361373, jul.-dez. 2014. Disponível em: https://www.revistasuninter.com/intersaberes/index.php/revista/article/view/642. Acesso em: 18 set. 2020.

SILVA, S. B.; OBANDO, I. M. Hábito da leitura através de filmes no ensino de Lingua Portuguesa: um olhar sobre esta prática com alunos do $2^{\circ}$ ano "6" do Ensino Médio da Escola Estadual Duque de Caxias em Tabatinga-AM. 2019. 20 f. Trabalho de Conclusão de Curso (Graduação em Letras) - Universidade do Estado do Amazonas, Amazonas, 2019. Disponível em: http:/ / repositorioinstitucional.uea.edu.br/handle/riuea/1415. Acesso em: 31 mar. 2021.

SILVA, A.; SILVA, L.; PENEDO, M.; SILVA, I. A produção de vídeo em uma turma de Pedagogia em Arapiraca. Congresso de Inovação Pedagógica em Arapiraca, 1, UFAL, Arapiraca/AL, p. 18-22, mai. 2015. Disponível em: http://www.seer.ufal.br/index.php/cipar/article/view/1977. Acesso: 2 maio 2020.

SOUZA E SILVA, L. Um método para produção de videoaulas no contexto educacional. 2018. 155 f. Dissertação (Mestrado) - Universidade Federal do Mato Grosso, Cuiabá/MT, 2018. Disponível em: https://www1.ufmt.br/ufmt/unidade/userfiles/\%20publicacoes/947abb41874cabcc22154efcb1b2dd45.pdf. Acesso em: 02 mai. 2020.

SUPERPROF. Razões para aprender a língua latina no colégio. Blog. 04 fev. 2019. Disponível em: https://www.superprof.com.br/blog/estudos-do-idioma-latino-no-ensino/. Acesso em: 31 mar. 2021.

TRANSPARENT LANGUAGE. Latin Language: Ten Latin Spells From Harry Potter. Por Brittany Britanniae. 7 may 2014. https://blogs.transparent.com/latin/ten-latin-spells-from-harry-potter/ UFBA - Universidade Federal da Bahia - Instituto de Letras. Latinitas Brasil. 2013. Disponível em: https://www.latinitasbrasil.org/. Acesso em: 31 mar. 2021.

UFBA - Universidade Federal da Bahia. Método de ensino de latim desenvolvido na UFBA será adotado em cursos da USP. 10 nov. 2015. Disponível em:

https://www.ufba.br/ufba_em_pauta/m\%C3\%A9todo-de-ensino-de-latim-desenvolvido-naufba-ser\%C3\%A1-adotado-em-cursos-da-usp. Acesso em: 31 mar. 2021. 
UFRGS - Universidade Federal do Rio Grande do Sul. NELE - Núcleo de Ensino de Línguas em Extensão. Como aprender latim de uma forma agradável? 01 jan. 2021. Disponível em: http://www.ufrgs.br/nele/12.-idiomas/latim/como-aprender-latim-de-uma-forma-agradavel . Acesso em: 31 mar. 2021.

UFRGS - Universidade Federal do Rio Grande do Sul. Omnia. 2012. Disponível em: https:// siteomnia.wixsite.com/omnia. Acesso em: 31 mar. 2021.

VICTIONARIUM LATINUM. Victionarium Latinum. 18 mar. 2019. Disponível em: https://la.wiktionary.org/wiki/Victionarium:Pagina_prima. Acesso em: 31 mar. 2021.

VOTTO, R. R. O Cinema no Ensino de Geografia. 2017. 50 f. Trabalho de Conclusão de Curso (Graduação em Pedagogia) - Universidade Federal de Rio Grande, Rio Grande, 2017. Disponível em: http:// repositorio.furg.br/handle/1/7993. Acesso em: 18 set. 2020.

WIZARDING WORLD. The etymology of Harry Potter spells. 4 jan. 2017. (originalmente publicado no Pottermore). Disponível em: https://www.wizardingworld.com/features/the-etymology-ofharry-potter-spells. Acesso em: 31 mar. 2021.

YATES, David. Harry Potter e o Enigma do Principe (filme). EUA. Warner Bros, 2009. 2h33min. YATES, David. Harry Potter e a Ordem da Fênix (filme). EUA. Warner Bros, 2007. 2h18min.

YATES, David. Harry Potter e as Relíquias da Morte - parte 1 (filme). EUA. Warner Bros, 2010. 2h26min.

YATES, David. Harry Potter e as Relíquias da Morte - parte 2 (filme). EUA. Warner Bros, 2011. 2h10min. 
Apêndice A - Coleta de dados - livros e filmes

Feitiços dos filmes:

Harry Potter e a Pedra Filosofal 00:37:10,3-00:37:12,3 Oculus reparo, 01:02:05,4-01:02:06, Alorromora. 01:02:11,5-01:02:15,2 Alorromora? 01:06:24,3-01:06:28,1 Vingardium leviosa. 01:06:29,6-01:06:32,0 Vingardium leviosa 01:06:32,4-01:06:34,5 Vingardium levios. 01:06:34,8-01:06:37,3 Vingardium levios. 01:06:55,0-01:06:56,9 Vingardium levios. 01:11:26,9-01:11:28,5 Vingardium leviosa! $01: 21: 34,2-01: 21: 36,3$ Lacarnum inflomat $\begin{array}{ll}01: 21: 34,2-01: 21: 36,3 & \text { Lacarnum inflamaras } \\ 01: 53: 54,7-01: 53: 58,8 & \text { Petrificus totalus. }\end{array}$ 01:54:34,8-01:54:36,5 Alorromora. $\begin{array}{ll}01: 54: 34,8-01: 54: 36,5 & \text { Alorromora. } \\ 01: 57: 39,6-01: 57: 40,9 & \text { Lumus solem. }\end{array}$ 01:58:49,3-01:58:51,1 Alorromora!

Harry Potter e a Câmara Secreta *00:17:21,7-00:17:23 Oculus Reparo. 00:36:48,1-00:36:50,8 Peskipiski Pestenomi! 00:37:21,3-00:37:23,0 Inmobilus! 00:57:21,0-00:57:22,8 Finite Incantatem! 00:57:50,5-00:57:53,5 Braquiam Emendo 01:05:12,1-01:05:14,0 Expelliarmus 01:06:57,1-01.06.59,1 Everti Static 01:07:10,4-01:07:12,1 Rictusempral. 01:07:23,5-01:07:26,0 Serpensortia! 01:07:41,8-01:07:44,0 Volate Ascenderel 01:08:27,0-01:08:29,8 Vipera Ivanesca. *00:00:43,8-00:00:46,1 Wingardium Leviosa. 00:13:55,8-00:13:58,5 Sisdam Apario. 00:14:04,2-00:14:06,3 Aranae Exumae. 00:29:28,2-00:29:30, $\quad$ Aranae Exumae! 00:30:03,7-00:30:05,9 Aranae Exumae! 00:43:05,6-00:43:07,5 Obliviate! 00:56:34,3-00:56:35,6 Detente!

Harry Potter e o Prisioneiro de Azkaban 00:00:31,5-00:00:33,7 Lumos Maxima. 00:00:36,0-00:00:38,8 Lumos Maxima. 00:00:58,9-00:01:00,5 Lumos Maxima. 00:01:02,8-00:01:04,7 Lumos Maxima. 00:01:06,6-00:01:08,5 Lumos Maxima! 00:40:53,1-00:40:54,6 Riddikulus! 00:40:54,8-00:40:56,9 Riddikulus! 00:40:59,8-00:41:02, $\quad$ Riddikulus! Riddikulus! 00:42:29,6-00:42:31, 7 Riddikulus! 00:43:18,9-00:43:20,7 Riddikulus! $00: 43: 48,9-00: 43 \cdot 50,9$ Riddikulus! 00:44:18,8-00:44:20,6 Riddikulu 00:56:23,1-00:56:25,9 Aresto momentum! 00:56:23,1-00:56:25, Aresto momentum! 01:08:23,0 $01.08 .28,4$ Expecto Patronum. 01:08:28,8-01:08:31,6 Expecto Patronum. 01:08:56,6-01:08:59,2 Expecto Patronum $\begin{array}{ll}\text { 01:09:00,0-01:09:03,3 } & \text { Expecto.Expecto.... } \\ \text { 01:09:03,6-01:09:05,3 } & \text { Expecto.... }\end{array}$ 01:09:03,6-01:09:05,3 $\quad$ Expecto.... 01:10:26,1-01:10:29,4 $\quad$ Expecto Patronum! $\begin{array}{ll}01: 10: 30,6-01: 10: 34,6 & \text { Expecto Patron } \\ 01: 31: 16,4-01: 31: 18,2 & \text { Expelliarmus! }\end{array}$ $\begin{array}{ll}01: 31: 16,4-01: 31: 18,2 & \text { Expelliarmus! } \\ \text { 01:32:59,4-01:33:02,4 } & \text { Expelliarmus! }\end{array}$ 01:32.59,401.33:02,4 Expelliarmu 01:34:11,8-01:34:13,6 Expelliarmus

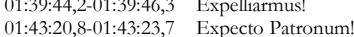
$01: 43: 20,8-01: 43: 23,7 \quad$ Expecto Pat $\begin{array}{ll}\text { 01:55:57,5-01:55:58,9 } & \text { Inmobulus! } \\ \text { 02:01:13,8-02:01:17,7 } & \text { Expecto Patronum! }\end{array}$ $\begin{array}{lll}02: 09: 43,8-02: 09: 45,5 & \text { Lumos. } \\ 02: 09: 43,8-02: 09: 45,5 & \text { Lumos. }\end{array}$ $\begin{array}{ll}\text { 02:09:43,8-02:09:45,5 } & \text { Lumos } \\ \text { 02:21:14,8-02:21:16,2 } & \text { Nox. }\end{array}$

Harry Potter e o Cálice de Fogo *00:03:41,0-00:03:43 Avada Kedavra. 00:11:53,5-00:11:55,6 Morsmordre. 00:12:41,0-00:12:42,5 Estupefaça! Estupefaçal 00:24:56,9-00:24:58,9 Engorgio. 00:24:59,2-00:25:00,8 Imperio.

\begin{tabular}{|c|c|}
\hline $00: 26: 35,9-00: 26: 36,9$ & Crucio! \\
\hline $00: 27: 20,8-00: 27: 22,8$ & Avada Kedrava. \\
\hline $00: 59: 04,6-00: 59: 06,4$ & Accio Firebolt! \\
\hline *00:19:47,9-00:19:50 & Ascendium. \\
\hline $00: 38: 19,6-00: 38: 21,4$ & Periculum. \\
\hline $00: 39: 02,5-00: 39: 03,9$ & Estupefaça. \\
\hline $00: 39: 04,3-00: 39: 06,1$ & Expeliarmus. \\
\hline $00: 40: 10,3-00: 40: 11,8$ & Reducto. \\
\hline $00: 42: 17,1-00: 42: 18,8$ & Avada Kedrava. \\
\hline $00: 49: 03,0-00: 49: 04,4$ & Crucio. \\
\hline $00: 49: 06,9-00: 49: 08,7$ & Crucio. \\
\hline $00: 49: 17,9-00: 49: 19,4$ & Expeliarmus. \\
\hline $00: 50: 20,8-00: 50: 23,2$ & Expeliarmus. \\
\hline $00: 50: 20,8-00: 50: 23,2$ & Avada Kedrava \\
\hline \multicolumn{2}{|c|}{ Harry Potter e a Ordem da Fênix } \\
\hline *00:59:07,9-00:59:10 & Expelliarmus! \\
\hline $00: 59: 24,2-00: 59: 25,2$ & Expelliarmus. \\
\hline $00: 59: 54,2-00: 59: 55,4$ & Estupefaça! \\
\hline 01:01:27,1-01:01:28,5 & Expelliarmus! \\
\hline 01:02:08,7-01:02:09,9 & Estupefaça! \\
\hline $01: 02: 19,5-01: 02: 20,8$ & Reducio! \\
\hline $01: 02: 34,3-01: 02: 35,4$ & Expelliarmus. \\
\hline 01:03:00,1-01:03:01,0 & Expelliarmus! \\
\hline $01: 03: 03,3-01: 03: 04,4$ & Expelliarmus! \\
\hline $01: 03: 07,2-01: 03: 08,5$ & Expelliarmus! \\
\hline $01: 03: 14,8-01: 03: 16,1$ & Reducto! \\
\hline $01: 03: 31,4-01: 03: 32,7$ & Expelliarmus! \\
\hline 01:03:38,7-01:03:39, 9 & Expelliarmus! \\
\hline *00:05:19,9-00:05:21 & Legilimens! \\
\hline $00: 16: 39,7-00: 16: 41,3$ & Expecto Patronum! \\
\hline $00: 17: 06,7-00: 17: 07,6$ & Expecto Patronum. \\
\hline $00: 18: 04,6-00: 18: 06,8$ & Bombarda Máxima! \\
\hline $00: 26: 56,5-00: 26: 57,8$ & Legilimens. \\
\hline $00: 27: 41,6-00: 27: 43,0$ & Legil... - Protego! \\
\hline $00: 27: 51,6-00: 27: 53,0$ & Expelliarmus. \\
\hline $00: 27: 56,0-00: 27: 57,1$ & Impedimenta. \\
\hline $00: 37: 44,1-00: 37: 45,7$ & Incarcerous! \\
\hline $00: 45: 23,7-00: 45: 25,0$ & Estupefaça! - Estupefaça! \\
\hline $00: 45: 49,1-00: 45: 51,0$ & Petrificus Totalus. \\
\hline $00: 46: 01,6-00: 46: 02,8$ & Estupefaça! \\
\hline $00: 46: 04,7-00: 46: 06,7$ & Estupefaça! - Estupefaça! \\
\hline $00: 46: 16,9-00: 46: 18,2$ & Estupefaça! \\
\hline $00: 46: 26,7-00: 46: 28,1$ & Reducto! \\
\hline $00: 51: 07,0-00: 51: 08,2$ & Expelliarmus! \\
\hline $00: 51: 17,4-00: 51: 18,8$ & Avra Kedavra! \\
\hline $00: 52: 10,1-00: 52: 11,4$ & Crucio! \\
\hline \multicolumn{2}{|c|}{ Harry Potter e o Enigma do Príncipe } \\
\hline $00: 25: 14,5-00: 25: 16,0$ & Petrificus Totalus. \\
\hline $00: 26: 22,0-00: 26: 23,7$ & Finite. \\
\hline $00: 28: 00,4-00: 28: 02,5$ & Episkey. \\
\hline $00: 45: 25,5-00: 45: 27,0$ & Confundus. \\
\hline $00: 46: 06,3-00: 46: 08,2$ & Sectumsempra? \\
\hline $01: 00: 57,5-01: 01: 01,8$ & Confundus. \\
\hline $01: 02: 55,1-01: 02: 56,6$ & Oppugno. \\
\hline $01: 06: 03,4-01: 06: 05,4$ & Harmonia Necteria Passus. \\
\hline 01:06:18,3-01:06:20,4 & Harmonia Necteria Passus. \\
\hline 01:06:22,4-01:06:24,4 & Harmonia Necteria Passus. \\
\hline $01: 16: 31,7-01: 16: 33,2$ & Estupefaça. \\
\hline 01:33:02,9-01:33:05,6 & Sectumsempra \\
\hline $01: 35: 03,7-01: 35: 05,3$ & Sectumsempra. \\
\hline $01: 35: 50,6-01: 35: 52,2$ & Vulnera Sanentur. \\
\hline $01: 35: 55,0-01: 35: 57,2$ & Vulnera Sanentur. \\
\hline $01: 35: 59,9-01: 36: 02,1$ & Vulnera Sanentur. \\
\hline $02: 00: 53,5-02: 00: 55,0$ & Aguamenti. \\
\hline $02: 01: 31,1-02: 01: 32,7$ & Lumus. \\
\hline $02: 02: 00,0-02: 02: 01,6$ & Lumus Maxima. \\
\hline $02: 02: 13,9-02: 02: 16,7$ & Estupefaça. \\
\hline $02: 02: 16,7-02: 02: 18,2$ & Sectumsempra. \\
\hline $02: 02: 18,2-02: 02: 21,4$ & Incarcerous. Estupefaça. \\
\hline $02: 03: 23,2-02: 03: 25,8$ & Partis Temporus. \\
\hline $02: 06: 40,5-02: 06: 42,1$ & Expelliarmus. \\
\hline
\end{tabular}

02:08:47,5-02:08:49,1 Avada Kedavra. 02:10:04,5-02:10:06,1 Incarcerous. 02:10:32,4-02:10:34,0 Sectusempra.

Harry Potter e as Relíquias da Morte - parte 1 00:02:23,2-00:02:24,8 Obliviate. 00:09:16,5-00:09:18,0 Avada Kedavra! 00:16:43,1-00:16:45,2 Estupefaça! 00:38:08,9-00:38:10,7 Expulso! 00:38:20,6-00:38:22,4 Petrificus Totalus! 00:38: $: 41,4-00: 39: 43,7$ Obliviate. 00:48:33,8-00:48.35,8 Expelliarmus 00:48:33,8-00:48:35,8 Expelliarmus! 00:54:47,3-00:54:52, Finite Incantatem. 00:54:47,3-00.54.52,2 00:56.54,6-00.56.55, Accio meda 01:01:22,0-01:01:23,2 Expecto Patronum! 01:03:06,6-01:03:08,4 Expelliarmus! 01:03:06,6-01.03.08,4 Expelliarmus! $\begin{array}{ll}\text { 01:04:18,1-01:04:20,2 } & \text { Accio Ditamno! } \\ \text { 01:05:18,0-01:05:20,4 } & \text { Protego Totalum }\end{array}$ 01:05:18,0-01.05:20,4 Protego Total 01:05:21,8-01:05:23,3 Salvio Hexia. 01:05:33,6-01:05:35,5 Protego Totalum. 01:05:37,9-01:05:42,2 Repello Trouxatum 01:05:37,9-01:05:42,2 Abaffiato. 01:05:57,401.05.59,6 Dissendium 01:06:13,2-01:06:15,1 Incêndio! 01:06:20,5-01:06:22,5 Expulso! 01:06:29,7-01:06:31,8 Diffindo 01:06:33,3-01:06:34,3 Reducto! 01:08:23,0-01:08:24,8 Avada Kedavral 01:19:28,2-01:19:30,8 Salvio Hexia. 01:19:34,2-01:19:36,7 Repello Trouxatum. 01:19:39,8-01:19:42,2 Salvio Hexia. 01:29:49,0-01:29:50,8 Lumus. 01:32:23,1-01:32:24,1 Confringol 01:36:44,6-01:36:46,2 Lumus. 01:37:27,3-01:37:28,7 Accio espada. 01:37:34,5-01:37:36,5 Diffindo. 01:46:30,5-01:46:31,5 Engorgio. 01:46:31,7-01:46:33,9 Reducio! 02:07:37,7-02:07:38,9 Expelliarmus! 02:07:40,3-02:07:41,4 Estupore!

Harry Potter e as Reliquias da Morte - parte 2 00:14:12,5-00:14:14,5 Imperio. 00:15:28,2-00:15:29,7 Aresto momentum! 00:16:03,9-00:16:05,9 Imperio! 00:17:19,7-00:17:20,9 Lumos. 00:17:34,5-00:17:36,1 Accio Horcrux 00:20:16,0-00:20:17,3 Reducto! 00:20:34,0-00:20:36,0 Relaxo! 00:21:52,6-00:21:53, Reducto 00:42:00,6-00:42:03,8 Piertotum Locomotor! 00:42:43,0-00:42:50,8 Protego Máxima. 00:42:43,0-00:42:50,8 Fianto Duri. 00:42:43,0-00:42:50,8 Repello Inmigotum. 00:42:51,0-00:42:52,4 Protego Máxima. 00:42:52,5-00:42:55, Fianto Duri. 00:42:52,5-00:42:55,8 Repello Inimigotum 00:42:56,0-00:42:56,7 Protego Máxima. 00:55:48,8-00:55:50,2 Estupore! 00:59:51,4-00:59:52,7 Expelliarmus! 00:59:53,0-00:59:54,0 Avada Kedavra! 00:59:54,2-00:59:55,2 Estupore! 01:03:27,9-01:03:29,9 Avada Kedavra! 01:06:23,1-01:06:24,4 Crucio! 01:18:15,5-01:18:17,0 Avada Kedavra! 01:19:44,0-01:19:45,5 Harmonia Nectere Passus. 01:20:12,8-01:20:15,5 Avada Kedavra. 01:22:13,1-01:22:16,5 Expecto Patronum. 01:31:15,9-01:31:17,6 Avada Kedavra! 01:42:54,6-01:42:56,4 Confringo! 
Feitiços dos livros

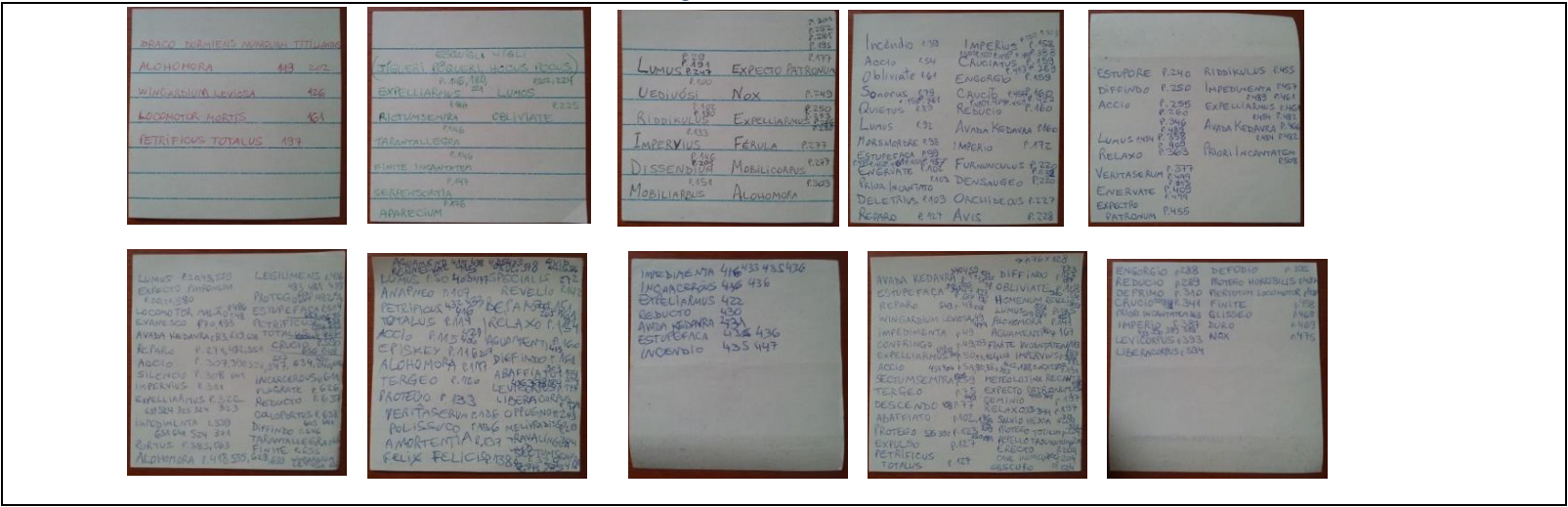

Harry Potter e a Pedra Filosofal

Capa Draco dormiens nunquam titillandus

20,119 alohomora

12 wingardium leviosa

16 locomotor mortis

19 petrificus totalus

Harry Potter e a Câmara Secreta

(jígueri pôqueri, hocus pocus, esquígli wígli)

$22,145,180$ expelliarmus

14 rictumsempra

14 tarantallegra

14 finite incantate

14 serpensorti

22, 202 lumos

22,202 lum

Harry Potter e o Prisioneiro de Azkaban

24, 29, 191 lumus

10 uediuósi

18,102 riddikulus

13 impervius

20, 146 dissendium

15 mobiliarbus

$30,177,195,281,282$ expecto patronum

24 nox

$28,250,253,266 \quad$ expelliarmus

27 mobilicorpus

30 alohomora

Harry Potter e o Cálice de Fogo

3 incêndio

5 accio

6 obliviate

7 sonorus

9 lumus

9 morsmordre

9, 49, 99,457,458,461,462 estupefaça

10 enervate

10 prior incantato

10 deletrius

12 reparo

15 engorgio

15 engorgio

16 avada kedavra

17 imperio

22 densaugeo

22 orchideous

22 orchi

24 estupore

25 diffind

36 relax

$36,89,153$ quietus

$45,358,409$ lumus

veritaseru

53,220 furnunculus

49,409 enervate

45 expecto pa
48, 457, 461 impedimenta

$48,159,269$ cruciatus

$48,160,422,456,458,474$ crucio/crucito

$48,255,260,346$ accio

48, 461, 482 expelliarmus

$48,466,482$ avada kedavra

50 priori incantatem

$50,158,388,483,495,500,501,502$ imperius

Harry Potter e a Ordem da Fênix

19, 70 evanesco

20,21,58 expecto patronum

31 impervius

48, 48 locomotor "malão"

$48,436,438,481$ legilimens

$55,271,482$ reparo

61 incarcerous

62 flagrate

63 reducto $324,325,524$,

$63,418,535,628$ alohomora

64 diffindo

64 diffindo

64, 638, 641 colloportus

65 tarantallegra

65 wingardium leviosa

$65,83,639$ avada kedavra

$65,307,390,521,547,634,640,646,650$ accio 65 ,

339, 371, 524, 641 impediment

$65,482,634,650$ protego

$65,514,635,638,639,640,649$ estupefaça

$65,526,641,642$ petrificus totalus

$65,590,648$ crucio

66,385 portus

Harry Potter e o Enigma do Príncipe

10 anapneo

11 alohomora

12 tergeo

13 protego

13 veritaserum

13 polissuco

13 amortentia

15 relaxo

16 aguamenti

17 liberacorpus

20, 116 episkey

21 oppugno

21 melivradisso

27,142 specialis
30 travalíngua

$30,151,161,205$ reparo

30, 174 abaffiato

38 quid agis

41 rennervate

41,161 diffindo

42 expeliarmus

$42,115,406$ accio 43reducto

43 avada kedavra

$43,114,416,432$ petrificus totalus

43, 174, 204, 284, 378 levicorpus

$43,378,433$ cruci

43,415 aguamenti

43,416 incarcerous

43, 416, 433, 435 impedimenta

43,435 estupefaça

$44,324,375,378,416,436$ sectumsempra

44,435 incendio

Harry Potter e as Relíquias da Morte

4 impedimenta

12 expulso

12 petrificus totalus

12 obliviate

$17,51,54,57,254,255,459$ avada kedavra

18 finite incantaten

19 meteolojinx recanto

19 geminio

20 repello trouxatum

20 repello

$21,102,186,204$ abaffiato

$21,102,186,20$

22 obscuro

24,75 tergeo

25,141 alohomora

$27,127,193$ diffindo

28 engorgio

28 reducio

31 deprimo

31, 131, 309 homenum revelio

31,204 salvio hexia

31,204 protego totalum

31,204 cave inimicum

36 priori incantatem

39 levicorpus

39 liberacorpu

39 defodi

$39,47,127,196,337,345,346$ estupefaça

39, 183 impervius

39, 197, 344 relaxo

43 protego horribilis

43 piertotum locomotor

43, 387, 388, 389, 390 imperio

45 finite

$45,51,80,88,142,188,202,219,252,393,404$ accio

45,77 descendo

46 glisseo

46, 167 aguamenti

47 nox

47,49 wingardium leviosa

$48,54,258$ reparo

$50,54,57,164,258,345,459$ expellinmus

50, 59 sectumsempra

50,135, 251, 271, 258, 392 lum

$50,196,197,405$, 32 lumus

$50,196,197,405$ expecto

$52,341,432,458$ crucio

$53,123,230,281,390$ protego 
Apêndice B - Feitiços da saga Harry Potter em Latim (ou Latinorum)

\begin{tabular}{|c|c|c|}
\hline Feitiço & Cena & Continua \\
\hline $\begin{array}{l}\text { Locomotor } \\
\text { Mortis }\end{array}$ & $\begin{array}{l}\text { HP1 Hermione salva Neville da maldição que Draco } \\
\text { jogou nele } \\
\underline{\text { dYkcp0Ykcx0 }}\end{array}$ & $\begin{array}{l}\text { Loco = colocar, estabelecer, edificar } \\
\text { Motio, motionis = significa ação ou ato de se mover } \\
\text { Mortis = s. sing. morte (genitivo) }\end{array}$ \\
\hline $\begin{array}{l}\text { Petrificus Tota- } \\
\text { lus }\end{array}$ & $\begin{array}{l}\text { HP1 Hermione petrifica Neville } \\
\text { vipmgWMhROk\&t }=72 \mathrm{~s}\end{array}$ & $\begin{array}{l}\text { Petra }=\text { rocha ou penhasco } \\
\text { Fícus (facio) = v. agir, realizar } \\
\text { Totus = adj. todo, inteiro, total } \\
\text { (flexão dos adjetivos) }\end{array}$ \\
\hline $\begin{array}{l}\text { Wingardium } \\
\text { Leviosa }\end{array}$ & $\begin{array}{l}\text { HP1 Hermione ensina a Rony a pronúncia correta } \\
\text { do feitiço } \\
\text { vipmgWMhROk\&t=37s }\end{array}$ & $\begin{array}{l}\text { Wing = Asa (inglês) } \\
\text { Ardium (arduus, arduum) = elevado, ou lugar alto } \\
\text { Leviosa (levis) = leve, ligeiro, veloz } \\
\text { Pronúncias: tradicional, eclesiástica, reconsti- } \\
\text { tuída latinitasbrasil.org/pronuncia }\end{array}$ \\
\hline $\begin{array}{l}\text { Aresto momen- } \\
\quad \text { tum }\end{array}$ & $\begin{array}{l}\text { HP1 Dumbledore salva Harry da queda no jogo de } \\
\text { quadribol } \\
\text { SbYjmD82Lqg } \\
\text { HP7-1 Hermione salva a si, Harry e Rony da queda } \\
\text { em Gringotes } \\
\text { isWBD76ZkVM }\end{array}$ & $\begin{array}{l}\text { Aresto }=\mathrm{v} . \text { deter } \\
\text { Momentum = s. momento (caso acusativo) }\end{array}$ \\
\hline $\begin{array}{l}\text { Lumus, } \\
\text { Lumus } M a \text { - } \\
\quad \text { xima, } \\
\text { Lumus Solem }\end{array}$ & $\begin{array}{l}\text { HP1 Hermione ilumina o visgo } \\
\text { vipmgWMhROk\&t }=87 \mathrm{~s} \\
\text { HP3 Harry ilumina livro para ler escondido nos } \\
\text { Dursley } \\
\text { 9PEIzXskHZg }\end{array}$ & $\begin{array}{l}\text { Lux, lucis = luz, brilho } \\
\text { Lumen }=\text { s. sing. n. luz, lâmpada } \\
\text { Maxima }=\text { adj. pl. f./n. grande, vasta, excelente } \\
\text { Solem }=\text { s. sing. n. sol (caso acusativo) } \\
\text { Concordância em gênero }\end{array}$ \\
\hline $\begin{array}{c}\text { Alarte } \\
\text { Ascendare }\end{array}$ & $\begin{array}{l}\text { HP2 Lockhart lança longe a cobra de Draco na aula } \\
\text { de combate } \\
\underline{\text { w3iZiTrjYpU }}\end{array}$ & $\begin{array}{l}\text { Ascendere }=\text { subir, escalar } \\
\text { Alarte }=\text { alarido } \\
\left(\text { verbos da } 2^{\mathbf{a}} \text {. conjugação) }\right.\end{array}$ \\
\hline Cistem aperio & $\begin{array}{l}\text { HP2 Tom Riddle abre o baú em que Hagrid } \\
\text { escondia Aragogue } \\
\text { y8618XZNl6s }\end{array}$ & $\begin{array}{l}\text { Aperio }=\mathrm{v} . \text { abrir, } \text { descobrir, revelar } \\
\text { Cistam }=\mathrm{s} . \text { cesta }, \text { caixa (caso acusativo) }\end{array}$ \\
\hline $\begin{array}{l}\text { Finite Incanta- } \\
\text { tem }\end{array}$ & $\begin{array}{l}\text { HP2 Hermione para o balaço que quebra o braço de } \\
\text { Harry } \\
\text { sXJSzx 1ahY }\end{array}$ & $\begin{array}{l}\text { Finite (finio, finire })=\mathrm{v} \text {. imperativo } 2^{\mathrm{a}} \cdot \mathrm{p} . \mathrm{pl} \text {. finalizai } \\
\text { Incantationem (Incantatio, incantationis) }=\text { encanta- } \\
\text { mento (acusativo) }\end{array}$ \\
\hline Aranea exumae & $\begin{array}{l}\text { HP2 Harry afasta as aranhas do carro voador na flo- } \\
\text { resta proibida } \\
\underline{1 \operatorname{lghY} 1 \mathrm{CI}-\mathrm{r} 8}\end{array}$ & $\begin{array}{c}\text { Araneae (aranea) }=\text { s. sing. fem. aranha (acusativo) } \\
\text { Exumai (exuo, exuere })=\text { despir }\end{array}$ \\
\hline Accio & $\begin{array}{l}\text { HP4 Harry convoca a Firebolt } \\
\text { ROVjUuAVWyg }\end{array}$ & $\begin{array}{c}\text { Accio }=\mathrm{v} \cdot \mathbf{1}^{\mathrm{a}} \cdot \mathrm{p} \cdot \operatorname{sing} \cdot \text { no presente }-(\mathrm{eu}) \text { convoco, } \\
\text { mando vir } \\
\left(\text { verbos da } 3^{\mathrm{a}} \cdot \text { conjugação }\right)\end{array}$ \\
\hline $\begin{array}{l}\text { Ascendio As- } \\
\text { cendium }\end{array}$ & $\begin{array}{c}\text { HP4 Harry se alça para sair do lago no Torneio } \\
\text { Tribruxo } \\
\text { Veg6 HofNas }\end{array}$ & $\begin{array}{c}\text { Ascendere }=\text { subir, escalar } \\
\text { Ascendo, ascendium = acima, para cima } \\
\left(\text { verbos da } 2^{\mathbf{a}} \text {.conjugação) }\right.\end{array}$ \\
\hline $\begin{array}{l}\text { Bombarda, } \\
\text { Bombarda } \mathrm{Ma}- \\
\text { xima }\end{array}$ & $\begin{array}{l}\text { HP3 Hermione destroi a porta (obstáculo) da Torre } \\
\text { Negra } \\
\text { u9zOS4tncVU } \\
\text { HP5 Umbridge destroi a porta (obstáculo) da Sala } \\
\text { Precisa } \\
\text { 97RkWfqpenY }\end{array}$ & $\begin{array}{l}\text { Bombarda = bombarda, canhão, torpedo } \\
\text { Maxima = excelente, grande } \\
\text { (concordância de gênero da } \mathbf{1}^{\mathbf{a}} \text {. declinação) }\end{array}$ \\
\hline Confringo & $\begin{array}{l}\text { HP7 Harry ressuscita e ataca Voldemort e seus se- } \\
\text { guidores } \\
\text { Ew1dczg3G64 }\end{array}$ & $\begin{array}{l}\text { Confringo, confringere - quebrar } \\
\text { Frango, frangere - quebrar } \\
\text { (verbos da } \mathbf{1}^{\mathbf{a}} \text {. conjugação) }\end{array}$ \\
\hline Confundus & $\begin{array}{l}\text { HP4 Hermione confunde Cormac no teste para go- } \\
\text { leiro } \\
\text { rmB8ALhdw9I }\end{array}$ & $\begin{array}{l}\text { Confundo }=\mathrm{v} . \text { misturar } \\
\text { Confusus }=\text { adj. confuso } \\
\text { (Latinorum e confusões) }\end{array}$ \\
\hline
\end{tabular}


Dossiê Educação e Cinemeỏntrufformativos

\begin{tabular}{|c|c|c|}
\hline Crucio & $\begin{array}{l}\text { HP4 Voldemort tortura Harry } \\
\text {-Pwc3QO8dHc }\end{array}$ & $\begin{array}{l}\text { Crucio = torturo }\left(1^{\mathrm{a}} \cdot \text { p. sing.) }\right. \\
\text { Maldição Cruciatus }=\text { (particípio passivo perfeito) } \\
\text { Crux, crucis = gen. de cruz ou da cruz (ato da cruz) }\end{array}$ \\
\hline Diffindo & $\begin{array}{l}\text { HP7-1 Harry ataca o medalhão } \\
\underline{\text { LxtK0usLXbY\&t }=460 \mathrm{~s}}\end{array}$ & $\begin{array}{l}\text { Dividere = v.t. dividir, separar em partes } \\
\text { (Latinorum) }\end{array}$ \\
\hline Estupefaça & $\begin{array}{l}\text { HP5 Duelo Hermione e Rony } \\
\underline{\text { rCGMWCljcqE }}\end{array}$ & $\begin{array}{l}\text { Estupefaça (stupefactus, - } \imath \text { ) }=\text { (adjetivo) surpreso,espan- } \\
\text { tado } \\
\text { Stupeo = v. ser atordoado, ser estorpecido, ser abis- } \\
\text { mado } \\
\text { Fio = v. fazer, causar que ocorra }\end{array}$ \\
\hline $\begin{array}{l}\text { Vipera Eva- } \\
\text { nesca }\end{array}$ & $\begin{array}{l}\text { HP2 Snape dissipa a cobra de Draco no duelo com } \\
\text { Gilderoy } \\
\text { omnRYzSSD0A }\end{array}$ & $\begin{array}{l}\text { Evanesco - v. evanescere } 1^{\mathrm{a}} \text { p. sing. evanescer, dissi- } \\
\text { par } \\
\text { Vipera }=\text { s. f. víbora, cobra } \\
\text { (caso acusativo) }\end{array}$ \\
\hline $\begin{array}{l}\text { Expecto Patro- } \\
\text { num }\end{array}$ & $\begin{array}{l}\text { HP3 Harry protege Sirius dos dementadores na flo- } \\
\text { resta } \\
\text { xlxxWFENWr8 } \\
\text { HP5 Harry ensina os colegas da Armada de Dumble- } \\
\text { dore } \\
\text { 34Rit1AnlVg\&t=1s }\end{array}$ & $\begin{array}{l}\text { expecto }=\text { espero, tenho esperança de } \\
\text { patronus }=\text { protetor ou defensor ou guardião } \\
\text { patronus: } \text { s. n. nominativo } \\
\text { patronum: } \text { s. n. acusativo }\end{array}$ \\
\hline Expelliarmus & 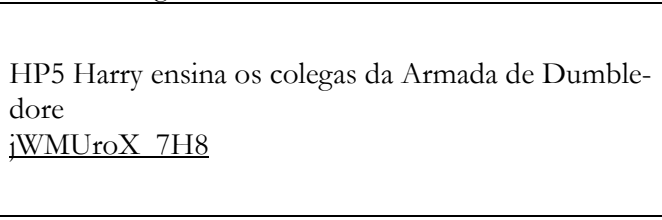 & $\begin{array}{l}\text { Expello (expellere) }=\text { expelir, expulsar, lançar para fora } \\
\text { de } \\
\text { Arma }=\text { armas } \\
\text { Mus }=\left(\text { desinência } 1^{\mathrm{a}} \text {.p.pl.) }\right. \\
\text { (Latinorum, caso acusativo, tempo presente, } \\
\text { plural) }\end{array}$ \\
\hline Fianto Duri & $\begin{array}{l}\text { HP7-2 Professores e pais de alunos protegem } \\
\text { Hogwarts } \\
\text { MBO4haWlOFQ }\end{array}$ & $\begin{array}{l}\text { Fictus }=\text { adj. falso; v. tornar feito, tornar formado } \\
\text { Duri }(\text { durus })=\text { duro, severo } \\
\text { (Latinorum) }\end{array}$ \\
\hline $\begin{array}{l}\text { Homenem / } \\
\text { Homenum re- } \\
\text { velio }\end{array}$ & $\begin{array}{l}\text { HP7-1 Hermione testa se há humanos no Largo } \\
\text { Grimmald } \\
\text { MBO4haWlOFQ }\end{array}$ & $\begin{array}{l}\text { Hominem }=\text { humano (acusativo) } \\
\text { Revelo }=\mathrm{v} \cdot \text { revelar } 1^{\mathrm{a}} \cdot \mathrm{p} \cdot \text { sing. }-(\mathrm{eu}) \text { revelo } \\
\text { (caso acusativo) }\end{array}$ \\
\hline Impedimenta & $\begin{array}{l}\text { HP6 Tiago imobiliza Snape } \\
\underline{\text { LxtKOusLXbY\&t }=634 \mathrm{~s}}\end{array}$ & $\begin{array}{l}\text { Impedimenta - s. pl. (impedimentum) obstáculos, barrei- } \\
\text { ras } \\
\text { (plural dos substantivos) }\end{array}$ \\
\hline Imperio & $\begin{array}{l}\text { HP7-2 Harry comanda os duendes em Gringotes } \\
\underline{\text { YszFj7u3C50 }}\end{array}$ & $\begin{array}{l}\text { Impero }=\text { reinar, governar, dirigir, dominar, imperar } \\
\text { Imperium, }-i=\mathrm{s} \text {. sing. } \mathrm{n} . \text { comando, ordem, governo } \\
\text { Imperio }=(\text { dativo) o controle para ti, o controle so- } \\
\text { bre ti } \\
\text { (caso dativo) }\end{array}$ \\
\hline Incarcerous & $\begin{array}{l}\text { HP5 Umbridge prende centauro que a ameeaça na } \\
\text { floresta } \\
\text { iZJG50vea6A }\end{array}$ & $\begin{array}{l}\text { Incarcerous }=\text { encarcerado } \\
\text { (adjetivos, particípios) }\end{array}$ \\
\hline Legilimens & $\begin{array}{l}\text { HP5 Snape ensina oclumência } \\
\text { V4hTVanqtBY }\end{array}$ & $\begin{array}{l}\text { Lego, legere }=\mathrm{v} . \text { ler (legi seria um potencial tempo pas- } \\
\text { sado }) \\
\text { Mens }=\text { s. mente } \\
\text { (tempo passado) }\end{array}$ \\
\hline $\begin{array}{l}\text { Levicorpus, } \\
\text { Liberacorpus }\end{array}$ & $\begin{array}{l}\text { HP5 Luna ataca um Comensal } \\
\text { 9u0E0ncU zI } \\
\text { HP6 Marotos levitam Snape } \\
\text { HP6 Lilian salva Snape }\end{array}$ & $\begin{array}{l}\text { Levare }=\text { levantar } \\
\text { Corpus }=\text { corpo (nominativo) } \\
\text { Libera }=\text { entregar } \\
\text { (nominativo vs. acusativo) }\end{array}$ \\
\hline Morsmordre & $\begin{array}{l}\text { HP4 Júnior conjura marca negra } \\
\text { ZLd4n7Tesk }\end{array}$ & $\begin{array}{l}\text { Mors }=\mathrm{s} . \text { voc. morte } \\
\text { Mordere }=\mathrm{v} . \text { morder } \\
\text { (vocativo, formação de palavras) }\end{array}$ \\
\hline Nox & $\begin{array}{l}\text { HP3 Harry apaga a luz quando vê Snape chegando } \\
\text { perto } \\
\underline{\text { uT9RdFL4SaE }}\end{array}$ & $\begin{array}{l}\text { Nox }=\text { s. f. noite } \\
\text { (origem de palavras da língua portuguesa) }\end{array}$ \\
\hline
\end{tabular}


Dossiê Educacão e Cinema: atos formativos

\begin{tabular}{|c|c|c|}
\hline Obliviate & $\begin{array}{l}\text { HP7-1 Hermione remove a si das memórias de seus } \\
\text { pais } \\
\text {-H0JParMivs\&t }=57 \mathrm{~s}\end{array}$ & $\begin{array}{l}\text { Obliviate (oblivio) }=\text { obliviar, esquecer, esquecimento } \\
\left(\text { conjugação na } 2^{\mathbf{a}} \text { p. pl.) (vos) no presente -ate }\right. \\
\text { Esqueceis ou esqueçais }\end{array}$ \\
\hline Oppugno & $\begin{array}{l}\text { HP6 Hermione ataca Rony } \\
\text { YquieSSduoA }\end{array}$ & $\begin{array}{l}\mathrm{Ob}=\text { ante, diante de, antes de } \\
\text { Pugna = briga, batalha, conflito } \\
\text { (prefixos latinos) }\end{array}$ \\
\hline Partis Temporus & $\begin{array}{l}\text { HP6 Dumbledore cria passagem no anel de fogo } \\
\text { contra os inferi } \\
\text { A0iQJXEaa28 }\end{array}$ & $\begin{array}{l}\text { Partis = s. sing. f. (genitivo) uma porção, um lado, } \\
\text { um pedaço } \\
\text { Temporis = s. sing. n. (genitivo) tempo }\end{array}$ \\
\hline Periculum & $\begin{array}{l}\text { HP4 Harry sinaliza posição de perigo de Fleur no } \\
\text { labirinto } \\
\text { dj0EsKdbeQQ }\end{array}$ & $\begin{array}{l}\text { Periculum }=\text { s. perigo, risco } \\
\text { (origem das palavras de língua portuguesa) }\end{array}$ \\
\hline $\begin{array}{l}\text { Piertotum } \\
\text { Locomotor }\end{array}$ & $\begin{array}{l}\text { HP7-2 McGonagal traz à vida as estátuas de } \\
\text { Hogwarts } \\
\text { 2Tpb1XyqGOQ }\end{array}$ & $\begin{array}{l}\text { Pier }=\text { amigo } \\
\text { Totum }=\text { inteiro } \\
\text { Locomotor = movimento de } \\
\text { Loco = v. colocar, estabelecer, edificar } \\
\text { Motio, motionis = ação ou ato de se mover (Latino- } \\
\text { rum) }\end{array}$ \\
\hline $\begin{array}{l}\text { Prior Incantato } \\
\quad=/= \\
\text { Priori Incanta- } \\
\quad \text { tem }\end{array}$ & $\begin{array}{l}\text { HP4 verificação do último feitiço lançado pela } \\
\text { varinha } \\
\text { gvNH-yIfwKg }\end{array}$ & $\begin{array}{l}\text { Prior }=\text { prévio, anterior, primeiro } \\
\text { Incantationem (Incantatio, incantationis) = encantamento } \\
\text { (acusativo) } \\
\text { (Concordância em gênero) }\end{array}$ \\
\hline $\begin{array}{l}\text { Protego To- } \\
\text { tallum, } \\
\text { Salvio Hexia, } \\
\text { Cave Inimicum }\end{array}$ & $\begin{array}{l}\text { HP7-1 e HP7-2 } \\
\text { XP2-W7EVpbg }\end{array}$ & $\begin{array}{l}\text { Protego }=\text { protejo }\left(1^{\text {a }} \text {. pessoa sing. }\right) \text { no tempo pre- } \\
\text { sente } \\
\text { Salveo }=\text { v. esteja com saúde } \\
\text { Hexia }=\text { s. sing. f. habilidade } \\
\text { Cave }=\text { cuidado, defesa } \\
\text { Inimicus = inimigo } \\
(\text { Latinorum })\end{array}$ \\
\hline Reducto & $\begin{array}{l}\text { HP5 Gina faz o Reducto } \\
\text { fEOuMCd5e9I\&t }=267 \mathrm{~s}\end{array}$ & $\begin{array}{l}\text { Reducto }=\text { reduzido, retirado } \\
\text { (particípio presente perfeito) (não é a } 1^{a} \cdot \text { p. sing.) }\end{array}$ \\
\hline Riddikulus & $\begin{array}{l}\text { HP3 Lupin ensina a combater bichos-papões com ri- } \\
\text { sadas } \\
\text { p2nEZQ9O9Ns }\end{array}$ & $\begin{array}{l}\text { Ridiculus = risível, absurdo, ridículo } \\
\text { (adjetivos) }\end{array}$ \\
\hline Sectumsempra & $\begin{array}{l}\text { HP6 Harry ataca Draco sem saber o efeito do feitiço } \\
\text { Xsa1B-RyyXQ }\end{array}$ & $\begin{array}{l}\text { Sectum }=\text { s. corte } \\
\text { Semper }=\text { adv. Sempre } \\
\text { (advérbios, formação de palavras) }\end{array}$ \\
\hline $\begin{array}{l}\text { Vulnera sanen- } \\
\text { tur }\end{array}$ & $\begin{array}{l}\text { HP6 Snape cura Draco } \\
\text { 7J 8EDisux8 }\end{array}$ & $\begin{array}{l}\text { Vulnera }=\mathrm{s} . \text { ferimentos } \\
\text { Sanetur }=(\text { conjuntivo }) \\
\left(3^{\mathrm{a}} \text { pessoa do singular do presente do subjuntivo }\right. \\
\text { passivo de sanare, sano }) \text { que fica sarado, que fica são }\end{array}$ \\
\hline $\begin{array}{l}\text { Lacarnum Infla- } \\
\text { mari }\end{array}$ & $\begin{array}{l}\text { HP1 Hermione toca fogo na roupa de Snape no qua- } \\
\text { dribol } \\
\text { vipmgWMhROk\&t=65s }\end{array}$ & $\begin{array}{l}\text { (Latinorum) } \\
\text { Inflamare }=\text { inflamar, tocar fogo } \\
\text { (acusativo) }\end{array}$ \\
\hline $\begin{array}{l}\text { Bracchium } \\
\text { emendo }\end{array}$ & $\begin{array}{l}\text { HP2 Lockhart tenta consertar o braço de Harry atin- } \\
\text { gido } \\
\text { tCtgw61P6S8 }\end{array}$ & $\begin{array}{l}\text { Bracchium = s. sing. n. braço } \\
\text { Emendo = s. sing. m./n. dat./abl. emendo, conserto, } \\
\text { corrijo } \\
\text { (caso dativo, caso ablativo) }\end{array}$ \\
\hline \multirow[t]{2}{*}{ Oculus reparo } & $\begin{array}{l}\text { HP1 Hermione conserta os óculos de Harry no trem } \\
\text { vipmgWMhROk\&t=29s } \\
\text { HP2 Hermione conserta os óculos de Harry na loja } \\
\text { vipmgWMhROk\&t }=94 \mathrm{~s}\end{array}$ & $\begin{array}{l}\text { Oculus }=\mathrm{s} . \mathrm{m} . \text { olho } \\
\text { Reparo }=\mathrm{v} . \text { reparar, consertar, emendar } \\
\text { (caso acusativo) }\end{array}$ \\
\hline & & Conclusão \\
\hline
\end{tabular}

Fonte: Adaptado de Transparent (2014), Exame (2016), Caldeirão (2019), Kühl (2020), Aficionados (2020), Victionarium (2020) com base na coleta e análise de dados. 